Alma Mater Studiorum - Università di Bologna DEPARTMENT OF ECONOMICS

Coherence, efficiency, and independence of the EU environmental policy system: results of complementary statistical and econometric analyses

Fabio Zagonari

Quaderni - Working Paper DSE N992

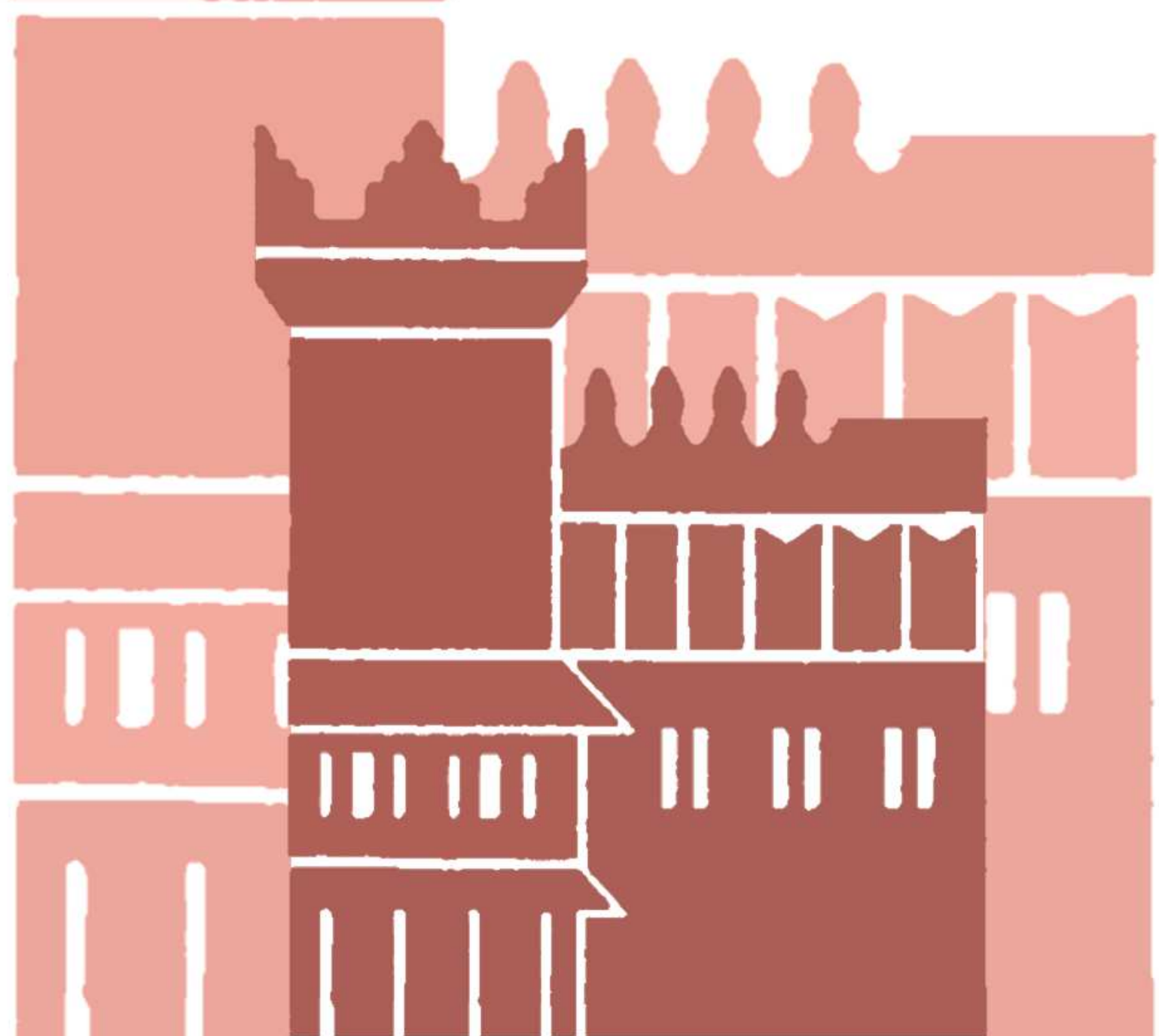




\title{
Coherence, efficiency, and independence of the EU environmental policy system: results of complementary statistical and econometric analyses
}

\author{
Fabio Zagonari \\ Dipartimento di Scienze Economiche, Università di Bologna, via Angherà 22, 47921 Rimini (Italy) \\ Phone: 00390541 434135, Fax: 00390541 434120, E-mail: fabio.zagonari@unibo.it
}

January 2015

\begin{abstract}
This paper presents the first empirical test of coherence (i.e., consistency of policies within a framework), efficiency (i.e., ability of policies to meet their objectives), and independence (i.e., logical priority of objectives over policies) of the overall EU environmental policy system. To do so, I applied statistical (cross-sectional and time series) and econometric (dynamic tri-probit) analyses to an original panel dataset, based on addressed issues rather than on implemented policies. In contrast with previous studies of single EU environmental policies, characteristics of the EU environmental policy, or EU environmental objectives, I found that the overall EU environmental policy system is coherent, efficient, and independent. Moreover, the evidence suggests that many issues are correlated: trans-boundary issues became more relevant in 2012, pollution production was more significant than resource use, and flow issues were more important than stock issues from 1995 to 2010. Finally, I show that few objectives overlapped: a "safe environment" objective (1987 to 1997) was preferred to a "greenhouse gas (GHG) reduction" objective (2003 to 2012, but pursued with a 2-year lag), although the latter has recently become preferred to the former. In addition, a "GHG reduction" objective was preferred to "a sustainable development" objective (1998 to 2002).
\end{abstract}

Keywords

European Union environmental policy; statistical analyses; cross-sections; time-series, dynamic triprobit

Q28, Q38, Q48, Q58

JEL classification 


\section{Introduction}

Many single EU environmental policies have been criticized. For instance, Clò et al. (2013) critiqued the Emission Trading System; Balana et al. (2011), Kampagrou et al. (2011), and Bourblanc et al. (2013) critiqued the Water Framework Directive; Hiedampää \& Bromley (2011) critiqued the biodiversity policies; Tol (2012) critiqued the energy policies; and Zagonari (2013) critiqued the Flood Directive. Moreover, many single characteristics of EU environmental policy have been criticized. For instance, Steurer et al. (2010) and Jackson (2011) highlighted the incoherence of legislation on sustainable development, and of biodiversity vs. renewable energy; Spencer \& Fazekas (2013) stressed a lack of equity by analyzing legislation on adaptation to climate change; and Aakre \& Rübbelke (2010) and Swinbank \& Daugbjerg (2013) highlighted inefficiency by considering legislation on climate change and biofuels, respectively. Finally, many single EU environmental objectives have been criticized. For instance, Spangenberg (2010) and Steurer \& Berger (2011) critiqued sustainable development; McLauchlan \& João (2012) and Sheate (2012) critiqued the safe environment objective; and Haug et al. (2010), Capros et al. (2011), and Brouwer et al. (2013) critiqued greenhouse gas $(G H G)$ reduction.

In contrast, few studies have scrutinized the overall EU environmental policy system in terms of its coherence (i.e., consistency of policies within a framework), efficiency (i.e., ability of policies to meet their objectives), and independence (i.e., logical priority of objectives over policies). For example, Nillson et al. (2012) stated that the EU environmental policy was incoherent. However, their analysis relied on a dataset in which 28 of the 53 items referred to the period before 1987. Moreover, Halpern (2010) concluded that EU environmental policy is dependent on and structured by its instruments, and that apart from the Environmental Impact Assessment and Emission Trading System, it was rarely innovative. However, the analysis was problematic because it relied exclusively on expert judgments, without verification from quantitative data, about legislation on biodiversity, waste treatment, water protection, and renewable energy. Finally, Aakre \& Rübbelke (2010) stated that EU environmental policy was often inefficient and that, from a geographical perspective, was always unequal. However, their analysis relied on simplistic parameters based on EU spending programs for adaptation to climate change.

The purpose of the present paper was to test the coherence, efficiency, and independence of the overall EU environmental policy system by applying statistical and econometric analyses to an original panel dataset. In addition, insights were obtained about the implicit relative importance attached by the EU to (possibly correlated) issues as well as the relative preferences for stated (possibly overlapping) objectives.

To support this analysis, I created a list of all EU environmental policies from the official EU Web site (http://www.eu/environment/legislation/summary) by focusing on the three legal hierarchies for policies with horizontal or vertical direct or indirect impacts: directives (DIR), regulations (REG), and decisions (DEC). I did not include opinions (e.g., guidelines, proposals, papers), recommendations, and communications, whether or not they were published in official EU journals. I also do not discuss cases or councils by the EU Court of Justice on environmental issues, since my purpose was not to assess the degree of implementation of or compliance with EU environmental policies.

Within this context, I identified four main groups of EU environmental policies that relate to optimal levels of pollution (i.e., TAX = taxes, STA = standards, PER = permits, SUB = subsidies) and three main groups of policies that relate to optimal uses (i.e., $\mathrm{GRO}=$ growth rate, TEC $=$ prices of substitutive technology, COS = marginal costs). I then introduced additional policies based on their relevance to the assumptions behind the competitive general equilibrium model (Cardenete et al., 2012): complete information (INF = policies to share information, i.e., to reduce information asymmetries), perfect information ( $\mathrm{UNC}=$ policies to reduce uncertainty, i.e., to tackle risk), perfect liability (RIG = policies to enforce rights), and a lack of interdependencies $(\mathrm{COO}=$ policies to improve cooperation). I will disregard policy measures in favor of competitiveness. This allowed me to test for coherence. Note that I classified policies according to their impact on the optimal 
production of pollution or the optimal use of resources; for example, policies for water quality relate to pollution production (POL).

Finally, I classified EU environmental policies into renewable (STO, stock) and non-renewable (FLO, flow) resource uses (RES), as well as stock (STO) and flow (FLO) pollution production (POL) and domestic (DOM) and trans-boundary (TRA) issues, by creating a combined category (BOT) for cases in which both sub-categories were plausible (i.e. BOT1 for both domestic or transboundary, BOT2 for both resource and pollution, and BOT3 for both stock and flow). For example, surface water is depicted as a domestic or trans-boundary (BOT1) renewable resource (RES) with a fixed natural growth rate (FLO). I then identified four EU environmental objectives: Objective 1, which was pursued from 1987 to 1997, was based on the Unique Environmental Act (1987) and was defined as "a safe environment". Objective 1 was related to DOM, POL, and FLO. Objective 2, which was pursued from 1998 to 2002, was based on the Amsterdam Treaty (1997) and was defined as "sustainable development". Objective 2 was related to BOT1, BOT2, and BOT3. Objective 3, which was pursued from 2003 to 2012, was based on the VI Environmental Action Programme (2001), and was defined as "GHG reduction". Objective 3 was related to TRA, POL, and STO. This allowed me to test for efficiency and independence. However, I disregarded Objective 4, which will be pursued after 2012 and was based on the Lisbon Treaty (2007). This objective refers to "a dematerialized economy", and should be studied in future research.

Table S1, Table S2 and Table S3 in the Online Supplementary Material summarize the classifications for DEC, DIR, and REG, respectively. Note that I will not consider the implementation (Ivanov \& Dobreva, 2011; Newig \& Koontz, 2013; Wolkinger et al., 2012), or the degrees of effectiveness or integration (Atkinson \& Klausen, 2011; Biesbroek et al., 2010; Dupont \& Oberthür, 2012; Jordan et al. 2012; Rietig, 2013; Steurer et al., 2010), of the EU environmental policy system, due to lack of reliable and comprehensive data.

\section{Methodology}

In the analysis presented in this paper, I first categorized the EU policies into groups to provide an overall statistical cross-section. Next, I performed a time-series analysis to determine how the various policy measures evolved over time. Finally, I developed econometric models for the issues and the three objectives. Based on the results of these analyses, I provide an overall assessment of the EU environmental policy system.

The first three categories refer to the problem directly tackled. For example, gaseous pollutants from mobile machines can be classified as DOM, POL, and FLO, even though this relates to GHG. It is then possible to account for both the first and second most relevant policies. For example, DIR for gaseous pollutants from mobile machines is STA, even though an emission trading system has been introduced to cope with $\mathrm{CO}_{2}$ emissions.

I used the following simplifying assumptions to determine how laws fit within the overall categories:

- All conventions and protocols are classified as COO (first policy).

- All committees and frameworks are classified as INF and COO (first and second policies, respectively).

- All programs are DOM, BOT2, BOT3, COO, and INF (3 categories, first and second policies, respectively).

- All laws related to implementation and financing are classified as RIG (I policy).

- Public participation is included in DOM, BOT2, BOT3, INF, and RIG (3 categories, first and second policies, respectively).

- Genetically modified organisms (GMOs) are labeled TRA, RES, STO, and STA to identify them (3 categories and first policy, respectively).

- Wastewater is FLO, wastes are STO, surface or fresh water are FLO, and groundwater is STO (third category). 
- Climate change ( $\mathrm{CO}_{2}$ emission) issues are TRA, POL, STO, and PER (3 categories and first policy, respectively).

- Renewable (green) energy issues are DOM, RES, FLO, and TEC (3 categories and first policy, respectively).

- Bio-fuels are DOM, RES, FLO, and STA (3 categories and first policy, respectively).

- Regional policies on resources are BOT1 (e.g., the Arctic Ocean; first category).

Note that EU policies towards other countries are not considered, unless they are specifically mentioned in DEC, DIR, or REG.

\section{Results}

\subsection{Statistical cross-section analysis}

If STA (mostly DIR) for pollution production and GRO (mostly REG) for resource uses are disregarded in Table 1, some EU policies can be identified:

- DIR-POL-PER identifies the GHG emission allowance trading scheme (i.e., the EU Emissions Trading System DIR2003/87).

- DIR-RES-UNC identifies the flood management and evaluation directive (DIR2007/60).

- DIR-POL-TAX identifies the taxation of heavy goods vehicles (i.e., the Euro-vignette directive DIR1999/62).

- DIR-BOT2-TAX identifies the EU framework for the taxation of energy products and electricity (DIR2003/96)

- DIR-RES-INF includes water protection and management (i.e., the Water Framework Directive DIR2000/60) as the only item with both domestic and trans-boundary (BOT1) and both stock and flow (BOT3) categories, and the strategy for the marine environment (i.e., the Marine Strategy Framework DIR2008/56) as the only item with both domestic and trans-boundary (BOT1) and stock (STO) categories.

- DIR-RES-STA includes motor vehicles and the use of biofuels (DIR2003/30) with the FLO category, and GMO legislation with the STO category.

- DIR-RES-TEC refers to promotion of the use of energy from renewable sources (DIR2009/28).

- DIR-BOT2-RIG refers to Strategic Environmental Assessment (DIR2001/42) with the STO category, and liability and criminality legislation with the FLO category.

- DIR-BOT2-INF refers to Environmental Impact Assessment (DIR1985/337) with the DOM category, and the information access legislation with the domestic and trans-boundary (BOT1) categories.

- REG-BOT2-GRO identifies Integrated Coastal Management (REG2002/413).

- REG-RES-RIG refers to LIFE+ (REG2007/614) with the BOT1 and BOT3 categories, and legislation on fur trade and illegal logging with the FLO and STO categories, respectively.

- REG-BOT2-INF refers to the Eco-Management and Audit Schemes (REG2001/761, REG2009/1221) with the BOT1 and BOT3 categories, and to minimum inspection criteria in the FLO category.

Out of 79 complementary policies (i.e., those that fall within the COO, INF, RIG, UNC classifications), 28 aim at improving cooperation (COO), versus 36 that aim at sharing information (INF); the remaining 15 aim at tackling risks (UNC) and enforcing rights (RIG). My analysis of the second relevant policy, neglected in Table 1, shows that DIR disappears, while REG and DEC relate mainly to GRO (15 out of 28 ) and STA (11 out of 28$)$. Note that the only 2 TAX in DIR can be explained by the lack of a common EU fiscal policy. 
Table 1. Legislation categories for all issues. SUB was never suggested as a POL policy, and COS was never suggested as an RES policy.

\begin{tabular}{|l|c|c|c|c|c|c|c|c|c|c|}
\hline & COO & GRO & INF & PER & RIG & STA & TAX & TEC & UNC & TOT \\
\hline DEC & 25 & 1 & 7 & & 4 & 2 & & & & 39 \\
\hline BOT2 & 1 & & 3 & & 1 & & & & & 5 \\
\hline POL & 8 & & 4 & & 2 & 2 & & & & 16 \\
\hline RES & 16 & 1 & & & 1 & & & & & 18 \\
\hline DIR & & 4 & 16 & 1 & 5 & 60 & 2 & 1 & 2 & 91 \\
\hline BOT2 & & & 3 & & 3 & & 1 & & & 7 \\
\hline POL & & & 11 & 1 & & 55 & 1 & & 1 & 69 \\
\hline RES & & 4 & 2 & & 2 & 5 & & 1 & 1 & 15 \\
\hline REG & 3 & 7 & 13 & & 3 & 17 & & & 1 & 44 \\
\hline BOT2 & 2 & 1 & 3 & & & & & & & 6 \\
\hline POL & 1 & & 10 & & & 14 & & & 1 & 26 \\
\hline RES & & 6 & & & 3 & 3 & & & & 12 \\
\hline TOT (DEC+DIR+REG) & 28 & 12 & 36 & 1 & 12 & 79 & 2 & 1 & 3 & 174 \\
\hline
\end{tabular}

Table 2. Legislation on trans-boundary issues only. Compared with Table 1, COS and TEC disappear from the RES policies, TAX disappears as a POL policy, and UNC disappears as a context policy.

\begin{tabular}{|l|c|c|c|c|c|c|c|}
\hline & COO & GRO & INF & PER & RIG & STA & TOT \\
\hline DEC & 8 & & 1 & & & 2 & 11 \\
\hline POL & 3 & & 1 & & & 2 & 6 \\
\hline RES & 5 & & & & & & 5 \\
\hline DIR & & 4 & 1 & 1 & & 6 & 12 \\
\hline POL & & & 1 & 1 & & 2 & 4 \\
\hline RES & & 4 & & & & 4 & 8 \\
\hline REG & 1 & 4 & 1 & & 1 & 9 & 16 \\
\hline POL & 1 & & 1 & & & 6 & 8 \\
\hline RES & & 4 & & & 1 & 3 & 8 \\
\hline TOT (DEC+DIR+REG) & 9 & 8 & 3 & 1 & 1 & 17 & 39 \\
\hline
\end{tabular}

Table 3. Legislation on stock issues only. Compared with Table 1, COS and TEC disappear as RES policies.

\begin{tabular}{|l|c|c|c|c|c|c|c|c|}
\hline & COO & GRO & INF & PER & RIG & STA & UNC & TOT \\
\hline DEC & 17 & 1 & 1 & & 1 & 1 & & 21 \\
\hline POL & 4 & & 1 & & & 1 & & 6 \\
\hline RES & 13 & 1 & & & 1 & & & 15 \\
\hline DIR & & 4 & 3 & 1 & & 24 & 1 & 33 \\
\hline POL & & & 2 & 1 & & 20 & 1 & 24 \\
\hline RES & & 4 & 1 & & & 4 & & 9 \\
\hline REG & & 6 & 2 & & 1 & 9 & 1 & 19 \\
\hline POL & & & 2 & & & 6 & 1 & 9 \\
\hline RES & & 6 & & & 1 & 3 & & 10 \\
\hline TOT (DEC+DIR+REG) & 17 & 11 & 6 & 1 & 2 & 34 & 2 & 73 \\
\hline
\end{tabular}


Comparing GRO with STA in Table 1, the overall summary, and in Table 2, the trans-boundary category, shows a reduction of GRO from 12 to 8 and of STA from 79 to 17, which suggests that resource uses are considered a trans-boundary issue whereas pollution production is considered a domestic issue. Comparing COO with INF in Table 1 and Table 2 shows a reduction of COO from 28 to 9 and of INF from 36 to 3, which suggests that sharing of information is considered a domestic goal, whereas improving cooperation is considered a trans-boundary goal.

Comparing GRO with STA in Table 1and in Table 3, which focuses on stocks, shows a reduction of GRO from 12 to 11 and of STA from 79 to 34, which suggests that resource uses are considered a stock issue (i.e., renewable resources), whereas pollution production is considered a flow issue (i.e., short-run pollution). Comparing COO with INF in Table 1 and Table 3 shows a reduction of COO from 28 to 17 and of INF from 36 to 6, which suggests that sharing information is considered to be a goal related to stock problems, whereas improving cooperation is considered to be a goal related to flow problems.

These results suggest that the proposed classification (by rows) is sufficiently fine-grained to identify single EU environmental policies (by columns), and it is consistent with the competitive general equilibrium set of assumptions, which is implicitly confirmed by the EU brochure on environmental policies (EC, 2013).

\subsection{Statistical time-series analysis}

In this section I use the competitive general equilibrium set of assumptions (complete information, perfect information, perfect liability, and a lack of interdependencies) to test for coherence (i.e., consistency of the policies within a framework). To do so, I will use the classification suggested in section 3.1 (by rows in the tables) to test for the efficiency (i.e., the ability of the policies to meet their objectives) of the EU environmental policy system.

Figure 1 shows that DIR were used before DEC, which were implemented before REG, and that REG was constantly increasing, whereas DIR and DEC decreased greatly and slightly, respectively. This suggests that once principles have been stated as DIR, the EU perceived the need to implement current environmental policies through direct impacts, and that they did so first by DEC and second by REG.

Figure 2 shows only 2 cases of TAX (1999 and 2003) and only 1 case of PER (2003), whereas the number of STA increased, although the increase slowed towards the end of the study period. Figure 3 shows only 1 case of TEC (2009), whereas GRO increased, though at a decreasing rate. Figure 4 shows only 3 cases of UNC (1993, 2007, and 2011), whereas INF increased, though at a decreasing rate, $\mathrm{COO}$ initially increased and then decreased, and RIG increased at an increasing rate.

Figure 1. Changes in the numbers of directives (DIR), regulations (REG), and decisions (DEC) from 1970 to 2011. Lines represent the results of polynomial regressions.

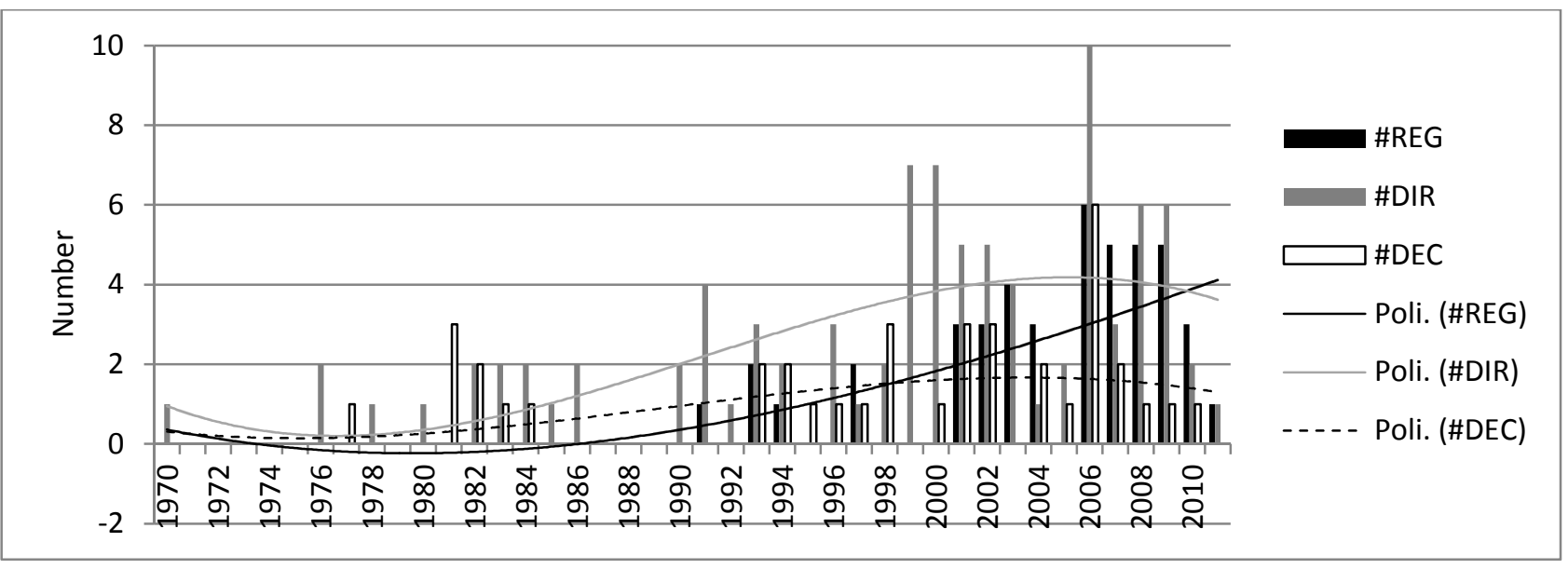


Figure 2. Changes in the number of pollution policies from 1970 to 2011 . Policies: STA, standards; TAX, taxes; PER, permits. Lines represent the results of polynomial regressions.

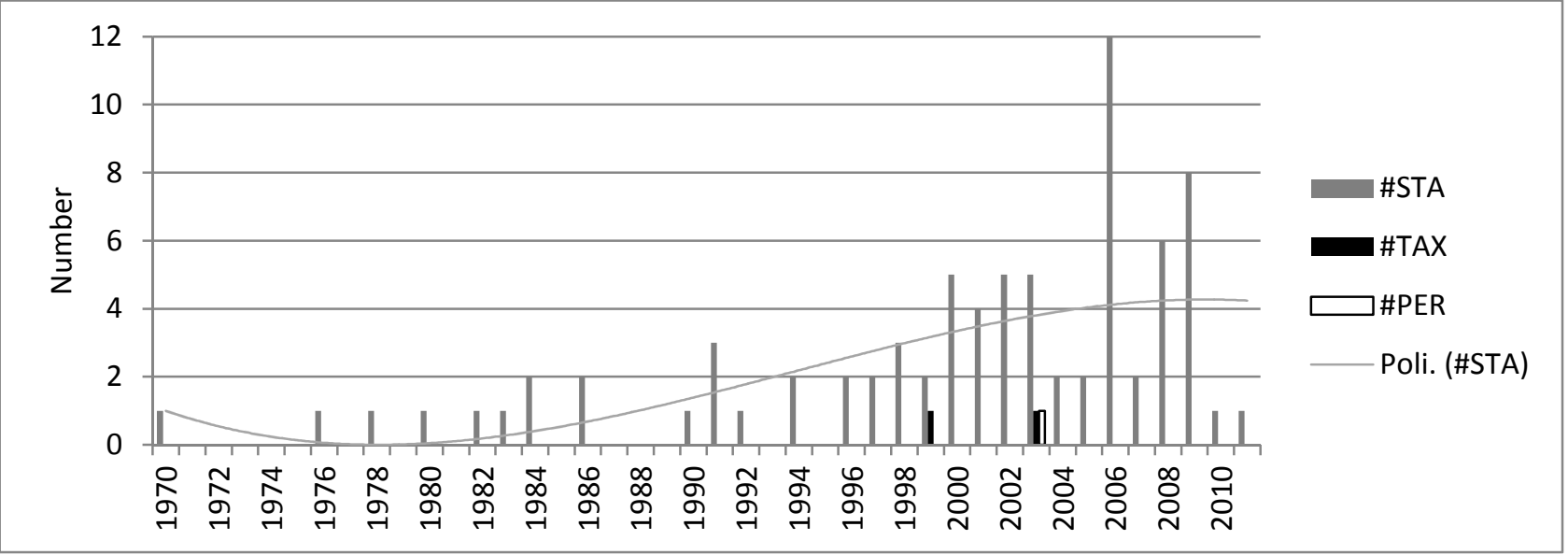

Figure 3. Changes in the number of resource policies from 1970 to 2011. Policies: GRO, growth rates; TEC, prices of substitutive technology. Lines represent the results of polynomial regressions.

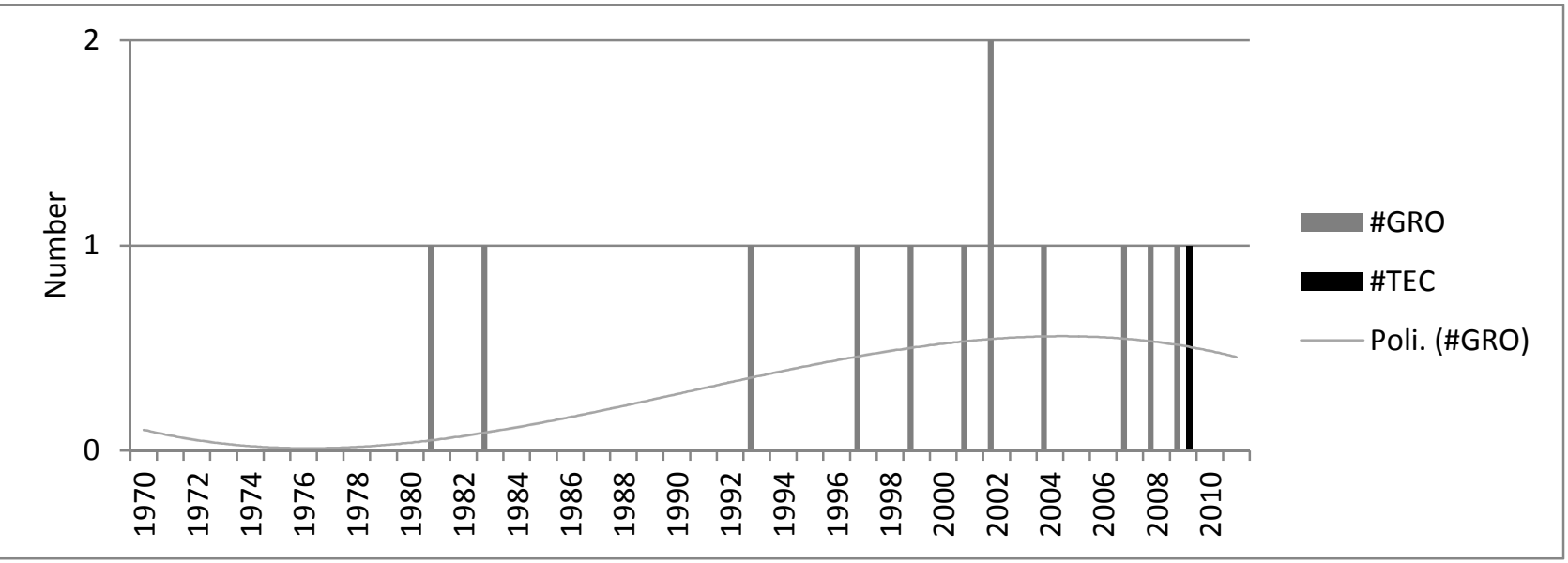

Figure 4. Changes in context policies from 1970 to 2011. Policies: COO, cooperation; INF, sharing of information, RIG, enforcement of rights; UNC, reduction of uncertainty. Lines represent the results of polynomial regressions.

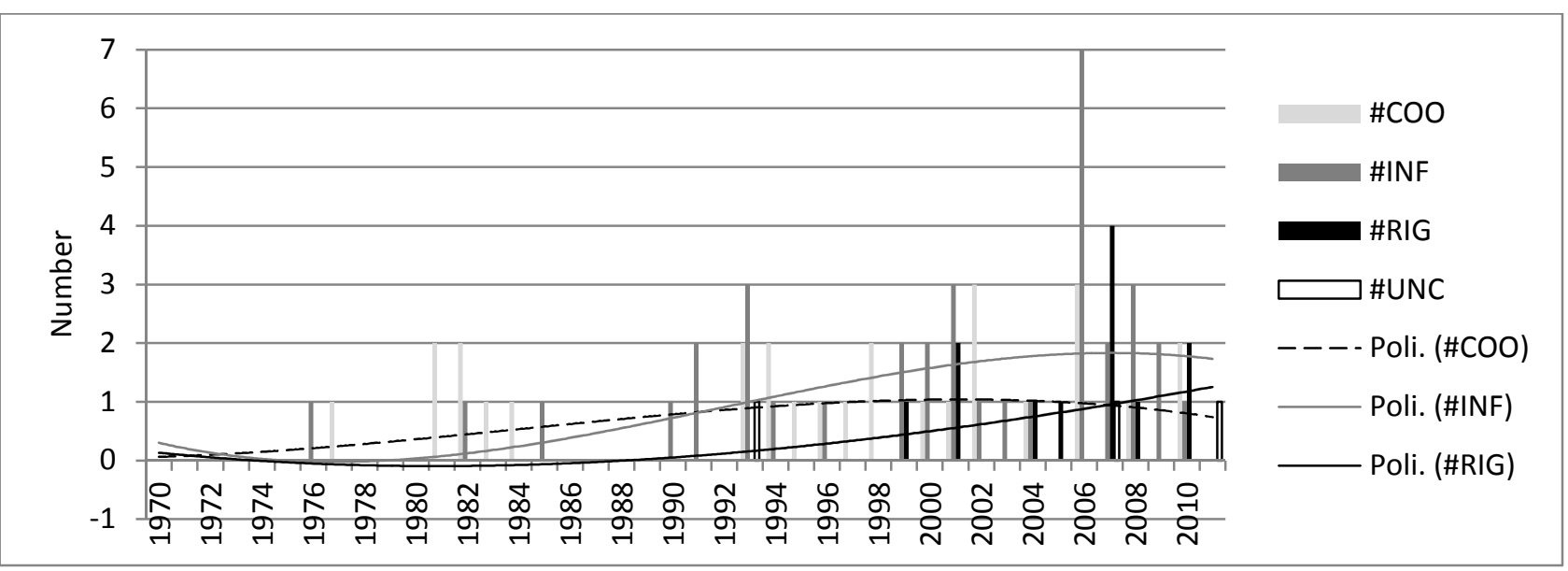


All policies can be assumed to be equivalent in terms of their ability to achieve all objectives within the competitive general equilibrium set of assumptions. Since EU policies are consistent with these assumptions, and since some EU environmental policies are implemented only a few times (e.g., PER and TEC with only 1 record each, TAX with only 2 records), the sample is unacceptably unbalanced, and it was necessary to use the classification of EU environmental policies by rows in Table 1 to test for efficiency.

Figure 5, Figure 6, and Figure 7 show the recent (1990 to 2011) evolution of the proportion of policies characterized by each feature over time $(t)$; in these graphs, 1 means that $100 \%$ of the policies introduced in year $t$ possessed the specified feature).

Figure 5. Changes in the relative importance of domestic (DOM), pollution (POL), and flow (FLO) issues from 1990 to 2011 (Objective 1). Lines represent the results of polynomial regressions.

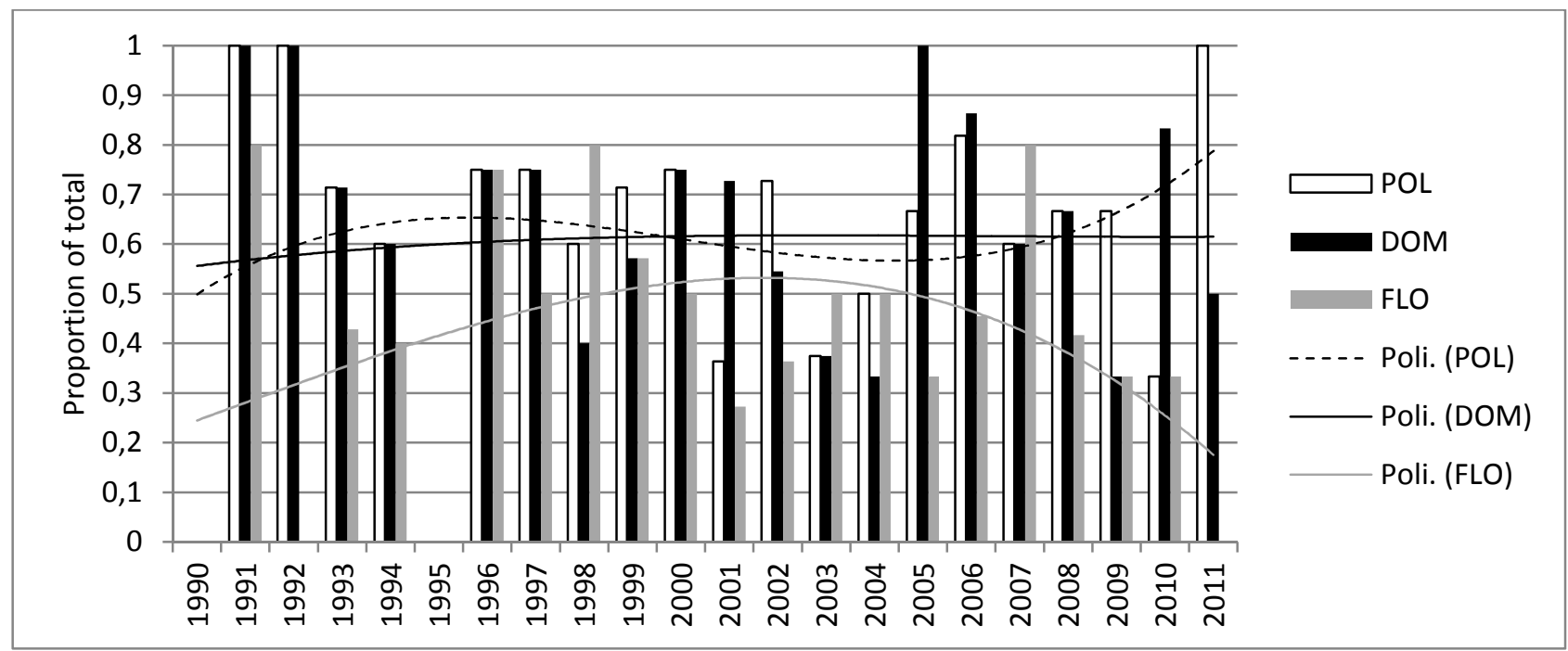

Figure 6. Changes in the relative importance of BOT1 (trans-boundary and domestic issues, TRA and DOM), BOT2 (pollution and resource issues, POL and RES), and BOT3 (stock and flow issues, STO and FLO) issues from 1990 to 2011 (Objective 2). Lines represent the results of polynomial regressions.

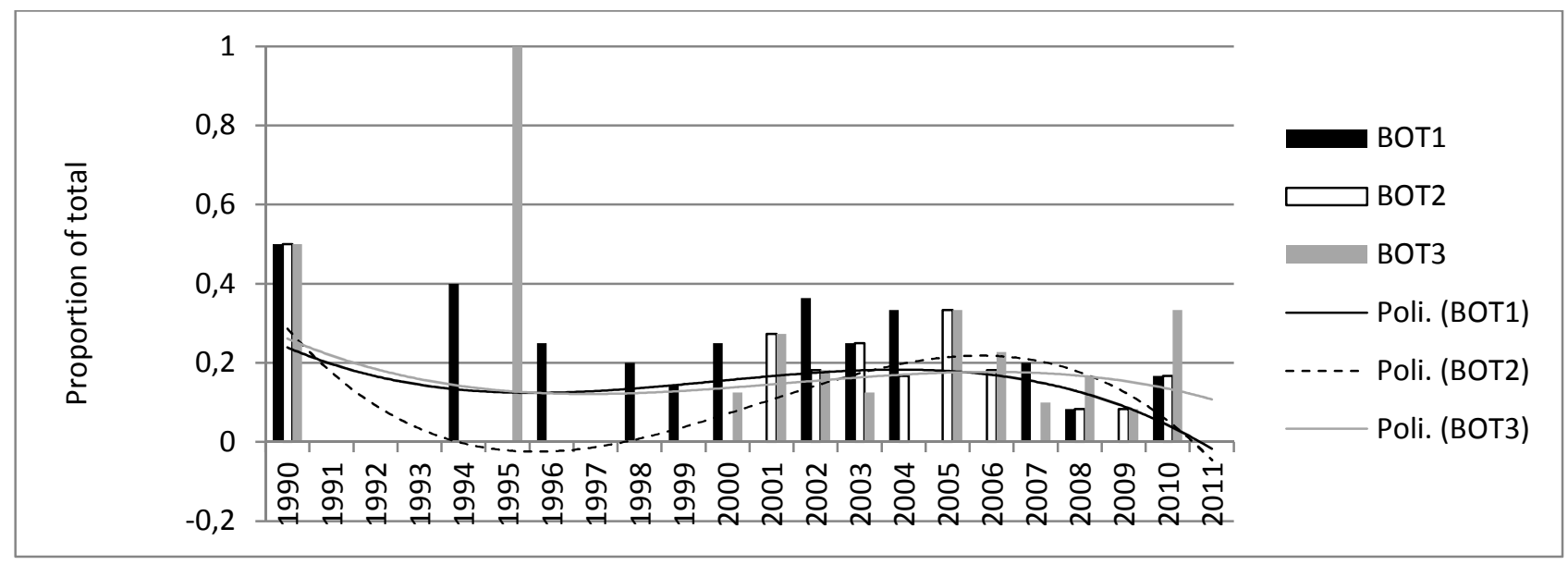


Figure 7. Changes in the relative importance of trans-boundary (TRA), pollution (POL), and stock (STO) issues from 1990 to 2011 (Objective 3). Lines represent the results of polynomial regressions.

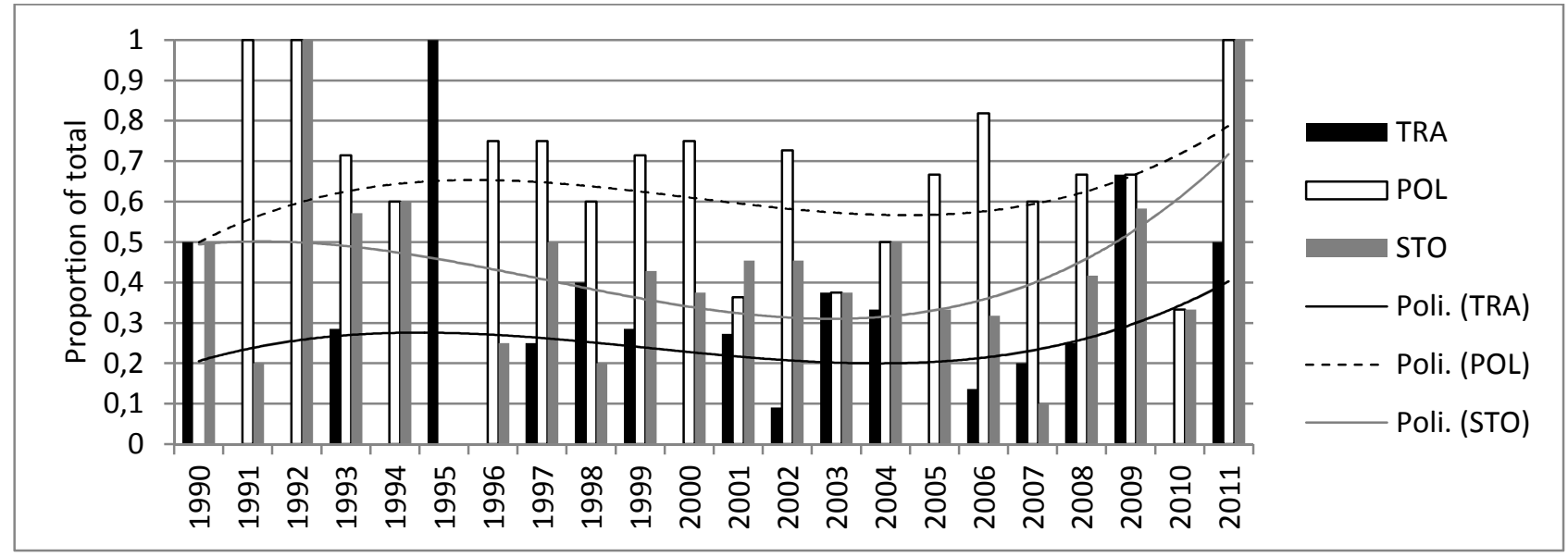

Based on this analysis, I obtained the following interpolation functions for each feature attached to each objective:
Objective 1:
$\operatorname{DOM}(\mathrm{t})=0.00002 \mathrm{t} 3-0.0008 \mathrm{t} 2+0.0139 \mathrm{t}+0.5428$
POL $(t)=0.0003 t^{3}-0.0085 t^{2}+0.0792 t+0.4286$
Objective 2:
FLO $(t)=-0.0001 t^{3}+0.0005 t^{2}+0.035 t+0.2094$
BOT2 $(t)=-0.0005 t^{3}+0.0165 t^{2}-0.1567 t+0.4271$
BOT3 $(t)=-0.0001 t^{3}+0.0054 t^{2}-0.0583 t+0.3143$
Objective 3:

$$
\begin{aligned}
& \text { TRA }(t)=0.0002 t^{3}-0.0057 t^{2}+0.046 t+0.1649 \\
& \text { POL }(t)=0.0003 t^{3}-0.0085 t^{2}+0.0792 t+0.4286 \\
& \text { STO }(t)=0.0002 t^{3}-0.0059 t^{2}+0.0233 t+0.4763
\end{aligned}
$$

Note that I have only considered the dynamics between 1990 and 2011, due to the lack of records in 2012 and because of the distortions in the interpolations that would result from the few records before 1990, while I have estimated third-degree polynomials to describe the three objective periods. Based on this analysis, the EU environmental policy appear to be efficient. Indeed, issues related to Objective 1 were mainly tackled before 1997; issues related to Objective 2 were increasingly tackled from 1997 to 2003, with no delay; and issues related to Objective 3 were increasingly tackled since 2005 , with a 2-year lag.

Figure 8. Implicit EU relative preferences for domestic versus trans-boundary issues (DOM/TRA) (thick), pollution versus resource issues (POL/RES) (dashed), and flow versus stock issues (FLO/STO) (thin) from 1990 to 2012 .

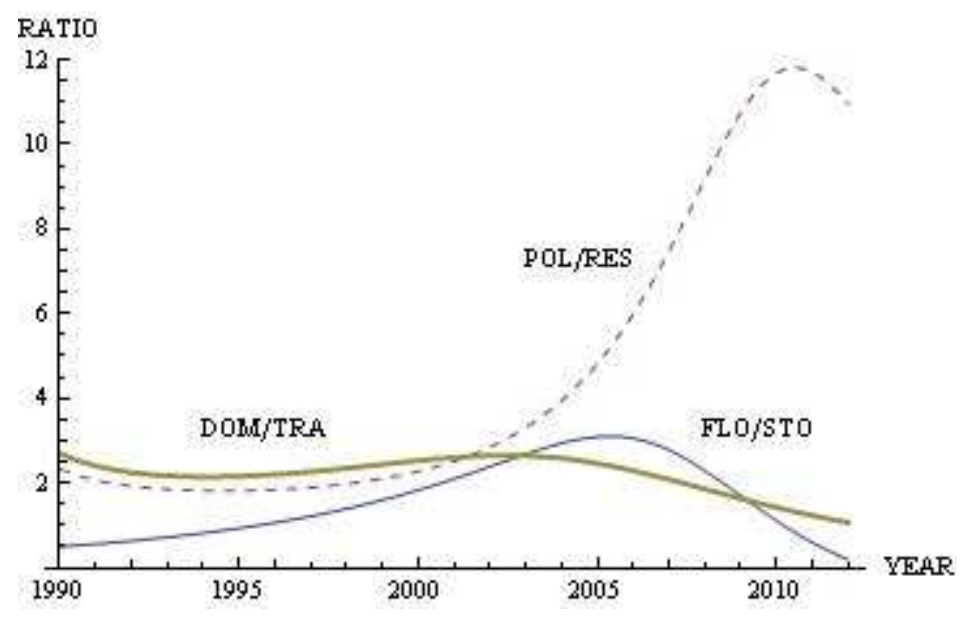


Figure 8 shows changes in the implicit relative preferences (i.e., importance) attached to the main issues from 1990 to 2012: DOM/TRA is initially larger than 1, then smaller; POL/RES is always larger than 1 and increases rapidly towards the end of the period; and FLO/STO is initially smaller than 1, increases gradually, then decreases again to values smaller than 1. Thus, trans-boundary issues became more relevant in 2012; pollution production was always considered to be more significant than resource uses, and became increasingly important over time; and flow issues were more important than stock issues from 1995 to 2010.

\subsection{Econometric analysis}

Although the statistical analysis performed in section 3.2 suggested that the EU environmental policy has been efficient in pursuing the stated objectives, it does not reveal the possibility of overlapping objectives, as suggested by the Lisbon Treaty (Steurer \& Berger, 2011). In addition, the analysis did not look for potential correlations between issues, and such correlations are to be expected in the implemented policies; for example, climate change policies such as the emission trading system should refer to both TRA and STO issues. In this section, I will develop and estimate an econometric model to test for these problems and to test the assumptions I made in section 3.2. Since some features are part of two or more objectives (e.g., POL belongs to both Objective 1 and Objective 3) and since all objectives can be assumed to be uncorrelated, even if they could potentially be combined, I will not estimate a nine-equation model. Instead, I will use a Taylor-type (backward-looking; Wang \& Handa, 2007) reaction function, which I estimated using a probit model (Huang \& Shen, 2002) for all three features related to an objective and for each stated objective $(j=1,2,3)$. In particular, I will obtain the maximum-likelihood estimation for the following 3 equation probit model of the three features:

$$
\begin{aligned}
& \operatorname{FEA}_{1 j}(t)=\text { probit }\left[\operatorname{OBJ}_{1}(t) \vee \operatorname{LOBJ}_{1}(t) \vee \mathrm{COBJ}_{12}(t) \vee \operatorname{LCOBJ}_{12}(t) \vee \mathrm{COBJ}_{123}(t) \vee \operatorname{LCOBJ}_{123}(t)\right. \text {, } \\
& \left.\mathrm{OBJ}_{2}(t) \vee \mathrm{LOBJ}_{2}(t) \vee \mathrm{COBJ}_{23}(t) \vee \mathrm{LCOBJ}_{23}(t), \mathrm{OBJ}_{3}(t) \vee \mathrm{LOBJ}_{3}(t)\right] \\
& \mathrm{FEA}_{2 j}(t)=\text { probit }\left[\mathrm{OBJ}_{1}(t) \vee \mathrm{LOBJ}_{1}(t) \vee \mathrm{COBJ}_{12}(t) \vee \operatorname{LCOBJ}_{12}(t) \vee \mathrm{COBJ}_{123}(t) \vee \operatorname{LCOBJ}_{123}(t)\right. \text {, } \\
& \left.\mathrm{OBJ}_{2}(t) \vee \mathrm{LOBJ}_{2}(t) \vee \mathrm{COBJ}_{23}(t) \vee \mathrm{LCOBJ}_{23}(t), \mathrm{OBJ}_{3}(t) \vee \mathrm{LOBJ}_{3}(t)\right] \\
& \operatorname{FEA}_{3 j}(t)=\operatorname{probit}_{[O B J}(t) \vee \operatorname{LOBJ}_{1}(t) \vee \mathrm{COBJ}_{12}(t) \vee \operatorname{LCOBJ}_{12}(t) \vee \mathrm{COBJ}_{123}(t) \vee \operatorname{LCOBJ}_{123}(t), \\
& \left.\mathrm{OBJ}_{2}(t) \vee \mathrm{LOBJ}_{2}(t) \vee \mathrm{COBJ}_{23}(t) \vee \mathrm{LCOBJ}_{23}(t), \mathrm{OBJ}_{3}(t) \vee \mathrm{LOBJ}_{3}(t)\right]
\end{aligned}
$$

where $\mathrm{FEA}_{1 j}(t)=1$ if the first issue (e.g., DOM) characterizing objective $j$ (e.g., $\mathrm{OBJ}_{1}$ ) is observed in a policy suggested at time $t$, and equals 0 otherwise; $\mathrm{OBJ}_{1}(t)=1$ from 1990 to 1997 and 0 otherwise when there is no lag; $\operatorname{LOBJ}_{1}(t)=1$ from 1991 to 1998 and 0 otherwise if there is a 1-year lag; $\operatorname{COBJ}_{12}(t)=1$ from 1990 to 2002 if there is no lag, but combined objectives 1 and 2; $\operatorname{LCOBJ}_{1}(t)=1$ from 1991 to 2002 and 0 otherwise if there is a 1-year lag, but combined objectives 1 and 2; $\operatorname{COBJ}_{123}(t)=1$ from 1990 to 2011 if there is no lag, but combined objectives 1, 2, and 3; and $\operatorname{LCOBJ}_{123}(t)=1$ from 1991 to 2011 and 0 otherwise if there is a 1-year lag, but combined objectives 1,2 , and 3 . The other independent variables are defined similarly for $\mathrm{OBJ}_{2}(t)$ and $\mathrm{OBJ}_{3}(t)$.

Table 4 summarizes these values for the feasible and meaningful independent variables. Note that $\mathrm{COBJ}_{123}$ amounts to a constant, whereas some independent variables can be obtained as a linear combination of other independent variables.

This three-equation dynamic probit model can depict crucial aspects such as lags, combinations of objectives, and coefficients that vary over time (Huang \& Lin, 2006), although it disregards irrelevant facets such as partial adjustments to a target (Clarida et al., 2000), smoothing (Huang \& Lin, 2006) or inertia (Melecky, 2012) in policies, changes in forecasts (Kishor \& Newiak, 2013), weak instruments (Shibamoto, 2008), and maximization of a specified objective function (Clarida et al., 1998). 
Table 4. Summary of all feasible and meaningful independent variables.

\begin{tabular}{|c|c|c|c|c|c|c|c|c|c|c|c|c|}
\hline Time & $\mathrm{OBJ}_{1}$ & $\mathrm{LOBJ}_{1}$ & $\mathrm{COBJ}_{12}$ & $\mathrm{LCOBJ}_{12}$ & $\mathrm{COBJ}_{123}$ & $\mathrm{LCOBJ}_{123}$ & $\mathrm{OBJ}_{2}$ & $\mathrm{LOBJ}_{2}$ & $\mathrm{COBJ}_{23}$ & $\mathrm{LCOBJ}_{23}$ & $\mathrm{OBJ}_{3}$ & $\mathrm{LOBJ}_{3}$ \\
\hline 1 & 1 & 0 & 1 & 0 & 1 & 0 & 0 & 0 & 0 & 0 & 0 & 0 \\
\hline 2 & 1 & 1 & 1 & 1 & 1 & 1 & 0 & 0 & 0 & 0 & 0 & 0 \\
\hline$\ldots$ & 1 & 1 & 1 & 1 & 1 & 1 & 0 & 0 & 0 & 0 & 0 & 0 \\
\hline 9 & 0 & 0 & 1 & 1 & 1 & 1 & 1 & 0 & 1 & 0 & 0 & 0 \\
\hline 10 & 0 & 0 & 1 & 1 & 1 & 1 & 1 & 1 & 1 & 1 & 0 & 0 \\
\hline$\ldots$ & 0 & 0 & 1 & 1 & 1 & 1 & 1 & 1 & 1 & 1 & 0 & 0 \\
\hline 13 & 0 & 0 & 0 & 0 & 1 & 1 & 0 & 0 & 1 & 1 & 1 & 0 \\
\hline 14 & 0 & 0 & 0 & 0 & 1 & 1 & 0 & 0 & 1 & 1 & 1 & 1 \\
\hline$\ldots$ & 0 & 0 & 0 & 0 & 1 & 1 & 0 & 0 & 1 & 1 & 1 & 1 \\
\hline
\end{tabular}

Note that this analysis refers to the literature on monetary reaction functions, since this subject shares many features with the study problem. Indeed, independent variables consist of "stated" or "unstated" objectives (in monetary reactions, a target interest rate; here, three issues: Objective $1=$ DOM, POL, FLO; Objective 2 = BOT1, BOT2, BOT3; Objective 3 = TRA, POL, STO). Moreover, dependent variables represent continuous instruments to achieve these objectives (in monetary reactions, the interbank lending rate for overnight loans; here, the importance attached to issues, to be tackled by alternative and equivalent policies). Finally, specified or unspecified exogenous random shocks are assumed to be independent and identically distributed (in monetary reactions, a pure random component to policy or an imperfect forecast idiosyncratic reserve demand; here, pressures to use some environmental policies or to achieve international visibility for the EU through its environmental policies). Table 5 shows that DOM and POL were significant and had larger coefficients for $\mathrm{OBJ}_{1}$, whereas FLO was not significant; in addition, the sum of the coefficients was significantly different from 1 (i.e., $\chi^{2}=0.01$ with probability $=0.9245$ ). Similar coefficients and significance levels were obtained for DOM, POL, and FLO if $\mathrm{OBJ}_{2}$ is replaced by $\mathrm{COBJ}_{12}$. Thus, Objective 1 appears to be insulated (i.e., pursued independently from other objectives), with DOM and POL as the only relevant features.

Table 5. Efficiency in pursuing Objective 1. Log-likelihood $-274.22243, P>$ Wald $\chi^{2}=0.0007$, number of observations $=152, \rho_{21}, \rho_{31}$, and $\rho_{32}$ are the estimated correlation between the DOM and POL equation error terms, the FLO and DOM equation error terms, the FLO and POL equation error terms, respectively. Statistically significant values are boldfaced.

\begin{tabular}{|c|c|c|c|c|c|c|c|}
\hline & & Coeff. & Std. Err. & $z$ & \multicolumn{2}{|c|}{$P>|z|$} & \multicolumn{2}{|c|}{$[95 \%$ Conf. Interval] } \\
\hline DOM & OBJ $_{1}$ & 0.550 & 0.263 & $\mathbf{2 . 0 9}$ & 0.036 & 0.035 & 1.065 \\
\hline & COBJ $_{23}$ & 0.190 & 0.179 & 1.06 & 0.288 & -0.160 & 0.540 \\
\hline & LOBJ $_{3}$ & 0.206 & 0.231 & 0.89 & 0.373 & -0.247 & 0.659 \\
\hline POL & OBJ $_{1}$ & 0.573 & 0.264 & $\mathbf{2 . 1 7}$ & 0.030 & 0.055 & 1.092 \\
\hline & $\mathrm{COBJ}_{23}$ & 0.192 & 0.178 & 1.08 & 0.279 & -0.156 & 0.541 \\
\hline & $\mathrm{LOBJ}_{3}$ & 0.244 & 0.231 & 1.06 & 0.289 & -0.208 & 0.697 \\
\hline \multirow{2}{*}{ FLO } & $\mathrm{OBJ}_{1}$ & -0.069 & 0.244 & -0.28 & 0.776 & -0.547 & 0.408 \\
\hline & $\mathrm{COBJ}_{23}$ & -0.102 & 0.176 & -0.58 & 0.561 & -0.446 & 0.242 \\
\hline & $\mathrm{LOBJ}_{3}$ & 0.000 & 0.228 & 0.00 & 0.998 & -0.446 & 0.447 \\
\hline & & & & & & & \\
\hline & $\rho_{21}$ & 0.611 & 0.094 & $\mathbf{6 . 5 1}$ & 0.000 & 0.394 & 0.763 \\
\hline & $\rho_{31}$ & 0.539 & 0.102 & $\mathbf{5 . 3 1}$ & 0.000 & 0.312 & 0.708 \\
\hline & $\rho_{32}$ & 0.570 & 0.102 & $\mathbf{5 . 6 1}$ & 0.000 & 0.339 & 0.737 \\
\hline
\end{tabular}

Table 6 shows that BOT1, BOT2 and BOT3 were all significant and had larger coefficients for $\mathrm{COBJ}_{2}$; in addition, the sum of the coefficients was 1 (i.e., $\chi^{2}=73.18$ with probability $<0.0001$ ). Replacing $\mathrm{OBJ}_{1}$ with $\mathrm{COBJ}_{12}$ or $\mathrm{COBJ}_{123}$ and replacing $\mathrm{COBJ}_{23}$ with $\mathrm{OBJ}_{2}$ produced unsatisfactory 
estimates, in terms of both the size and the significance of the coefficients. Thus, Objective 2 appears to be combined both with an earlier objective (i.e., $\mathrm{OBJ}_{1}$ is highly significant) and with a later objective (i.e., $\mathrm{COBJ}_{23}$ must be used rather than $\mathrm{OBJ}_{2}$ ), with BOT1, BOT2, and BOT3 all becoming crucial features.

Table 6. Efficiency in pursuing Objective 2. Log-likelihood -148.17416, $P>$ Wald $\chi^{2}<0.0001$, number of observations $=152, \rho_{21}, \rho_{31}$, and $\rho_{32}$ are the estimated correlation between the BOT2 and BOT1 equation error terms, the BOT3 and BOT1 equation error terms, the BOT3 and BOT2 equation error terms, respectively. Statistically significant values are boldfaced.

\begin{tabular}{|c|c|c|c|c|c|c|c|}
\hline & & Coeff. & Std. Err. & $z$ & \multicolumn{2}{|c|}{$P>|z|$} & \multicolumn{2}{|c|}{$[95 \%$ Conf. Interval] } \\
\hline BOT1 & OBJ $_{1}$ & -1.097 & 0.293 & -3.75 & 0.000 & -1.670 & -0.523 \\
\hline & COBJ $_{23}$ & -0.850 & 0.204 & $\mathbf{- 4 . 1 8}$ & 0.000 & -1.249 & -0.451 \\
\hline & LOBJ $_{3}$ & -0.521 & 0.292 & -1.78 & 0.075 & -1.094 & 0.052 \\
\hline BOT2 & OBJ $_{1}$ & -1.856 & 0.454 & -4.09 & 0.000 & -2.746 & -0.967 \\
\hline & COBJ $_{23}$ & -1.075 & 0.220 & $\mathbf{- 4 . 8 9}$ & 0.000 & -1.506 & -0.644 \\
\hline & LOBJ $_{3}$ & -0.077 & 0.287 & -0.27 & 0.788 & -0.640 & 0.486 \\
\hline BOT3 & OBJ $_{1}$ & -1.470 & 0.347 & -4.23 & 0.000 & -2.151 & -0.789 \\
\hline & $\mathrm{COBJ}_{23}$ & -1.075 & 0.221 & $\mathbf{- 4 . 8 6}$ & 0.000 & -1.509 & -0.641 \\
\hline & LOBJ $_{3}$ & 0.114 & 0.279 & 0.41 & 0.684 & -0.434 & 0.662 \\
\hline & & & & & & & \\
\hline & $\rho_{21}$ & 0.192 & 0.206 & 0.93 & 0.352 & -0.221 & 0.547 \\
\hline & $\rho_{31}$ & 0.242 & 0.194 & 1.25 & 0.211 & -0.155 & 0.572 \\
\hline & $\rho_{32}$ & 0.879 & 0.064 & $\mathbf{1 3 . 6 9}$ & 0.000 & 0.674 & 0.958 \\
\hline
\end{tabular}

Table 7 shows that TRA, POL, and STO all had significant and larger values for the coefficient of $\mathrm{LOBJ}_{3}$ : the sum of coefficients is 1 (i.e., $\chi^{2}=28.28$ with probability $<0.0001$ ). Replacing $\mathrm{OBJ}_{1}$ with $\mathrm{COBJ}_{12}$ or $\mathrm{COBJ}_{123}$ and replacing $\mathrm{OBJ}_{2}$ with $\mathrm{COBJ}_{23}$ produces unsatisfactory estimates in terms of both the size and the significance of the coefficients. Thus, Objective 3 appears to be insulated (i.e., pursued independently from other objectives), with TRA, POL, and STO all becoming crucial features.

Table 7. Efficiency in pursuing Objective 3. Log-likelihood $-\mathbf{2 6 0 . 7 3 4 3 5}, P>$ Wald $\chi^{2}<0.0001$, number of observations $=152, \rho_{21}, \rho_{31}$, and $\rho_{32}$ are the estimated correlation between the POL and TRA equation error terms, the STO and TRA equation error terms, the STO and POL equation error terms, respectively. Statistically significant values are boldfaced.

\begin{tabular}{|c|c|c|c|c|c|c|c|}
\hline & & Coeff. & Std. Err. & $z$ & \multicolumn{2}{|c|}{$P>|z|$} & \multicolumn{2}{|c|}{$[95 \%$ Conf. Interval] } \\
\hline TRA & $\mathrm{OBJ}_{1}$ & -0.960 & 0.275 & -3.49 & 0.000 & -1.499 & -0.421 \\
\hline & $\mathrm{OBJ}_{2}$ & -0.859 & 0.221 & -3.88 & 0.000 & -1.292 & -0.425 \\
\hline & $\mathrm{LOBJ}_{3}$ & -0.633 & 0.156 & $\mathbf{- 4 . 0 5}$ & 0.000 & -0.939 & -0.326 \\
\hline POL & $\mathrm{OBJ}_{1}$ & 0.509 & 0.249 & 2.04 & 0.041 & 0.021 & 0.997 \\
\hline & $\mathrm{OBJ}_{2}$ & 0.302 & 0.196 & 1.54 & 0.124 & -0.082 & 0.687 \\
\hline & $\mathrm{LOBJ}_{3}$ & 0.441 & 0.151 & $\mathbf{2 . 9 2}$ & 0.004 & 0.145 & 0.736 \\
\hline STO & $\mathrm{OBJ}_{1}$ & -0.134 & 0.232 & -0.58 & 0.565 & -0.589 & 0.322 \\
\hline & $\mathrm{OBJ}_{2}$ & -0.234 & 0.193 & -1.21 & 0.227 & -0.613 & 0.145 \\
\hline & $\mathrm{LOBJ}_{3}$ & -0.299 & 0.148 & $\mathbf{- 2 . 0 2}$ & 0.043 & -0.590 & -0.009 \\
\hline & & & & & & & \\
\hline & $\rho_{21}$ & -0.296 & 0.132 & $\mathbf{- 2 . 2 4}$ & 0.025 & -0.529 & -0.021 \\
\hline & $\rho_{31}$ & 0.748 & 0.080 & $\mathbf{9 . 4 0}$ & 0.000 & 0.547 & 0.867 \\
\hline & $\rho_{32}$ & -0.208 & 0.129 & -1.61 & 0.107 & -0.443 & 0.053 \\
\hline
\end{tabular}


Therefore, the econometric analysis confirms the previous statistical results:

- $\quad$ The EU adopted three different environmental policies during three different periods rather than a single policy that they fine-tuned over time; indeed, estimations based on a constant (i.e., $\mathrm{COBJ}_{123}$ ) and two dummy variables (i.e., $\mathrm{OBJ}_{2}$ and $\mathrm{OBJ}_{3}$ ) were rejected.

- $\quad$ The EU pursued its stated objectives; indeed, the significance and size of the coefficients were consistent with the relative importance of the issues in each environmental policy.

- The EU attempted a sustainable development objective (Objective 2) with no temporal lag, and a GHG reduction objective (Objective 3) with a small temporal lag: indeed, there is no Cholesky factorisation of the covariance matrix for the errors with a 2-year lags for OBJ3.

However, the econometric analysis adds some insights to the previous statistical results:

- Many issues are meaningfully correlated; indeed, significant positive correlations were observed between DOM and POL, DOM and FLO, and POL and FLO (i.e., $\rho_{21}, \rho_{31}$, and $\rho_{32}$ in Table 5); a significant negative correlation existed between TRA and POL (i.e., $\rho_{21}$ in Table 7 ); and significant positive correlations were observed between BOT2 and BOT3 (i.e., $\rho_{32}$ in Table 6), and TRA and STO (i.e., $\rho_{31}$ in Table 7).

- The approach to identify environmental policies adopted in this study is supported; indeed, the overall significance of the estimations was high (all Wald $\chi^{2}$ tests had $P<0.0001$ ).

- The objectives overlapped temporally only to a small extent; indeed, only the sustainable development objective (Objective 2) overlapped significantly with the GHG reduction objective (Objective 3).

Note that similar results were obtained (data not shown) by applying the Geweke-HajivassiliouKeane (GHK) smooth recursive conditioning simulator (Cappellari \& Jenkins, 2003), whereas introducing a constant to increase consistency amounts to using $\mathrm{COBJ}_{123}$.

However, the econometric analysis misses some results revealed by the statistical analysis:

- $\quad$ The relative importance of single issues in each policy over time.

- The identification of the year when a given issue became more or less important for a given objective.

- $\quad$ The specific lag time for tackling single issues in each policy.

In particular, the sum of the three interpolation functions that depict each objective, after transformation into scores in the interval $[0,1]$ by dividing the values by 3 (i.e., the maximum proportion achievable by the three issues that characterize an objective, each with a value of 1) allows estimation of changes in the relative preferences for the stated objectives over time, based on the assumption that all three objectives could be pursued simultaneously (ALLOBJ):

$$
\begin{gathered}
\mathrm{OBJ}_{1}(t)=[\mathrm{DOM}(t)+\mathrm{POL}(t)+\mathrm{FLO}(t)] / 3 \\
\mathrm{OBJ}_{2}(t)=[\mathrm{BOT} 1(t)+\mathrm{BOT} 2(t)+\mathrm{BOT}(t)] / 3 \\
\mathrm{OBJ}_{3}(t)=[\mathrm{TRA}(t)+\mathrm{POL}(t)+\mathrm{STO}(t)] / 3 \\
\operatorname{ALLOBJ}(t)=\mathrm{OBJ}_{1}(t)+\mathrm{OBJ}_{2}(t)+\mathrm{OBJ}_{3}(t)
\end{gathered}
$$

Figure 9 shows that Objective $1>$ Objective $3>$ Objective 2 for most of the study period, except for Objective 3 > Objective 1 starting in 2011. Objective 2 appears to be declining in importance before 1997, increases in importance until 2005, and then decreases to a relative importance of 0 by the end of the period. Thus, although a GHG reduction objective has been preferred to a safe environment objective only during the last year of the study period, the latter (Objective 1) has been preferred to the former (Objective 3), which in turn has been preferred to a sustainable development objective. Although this last objective (Objective 2) was pursued before it was formally stated, it quickly became unimportant towards the end of the study period. 
Figure 9. Changes in the values of the implicit relative preferences for the three stated objectives from 1990 to 2012.

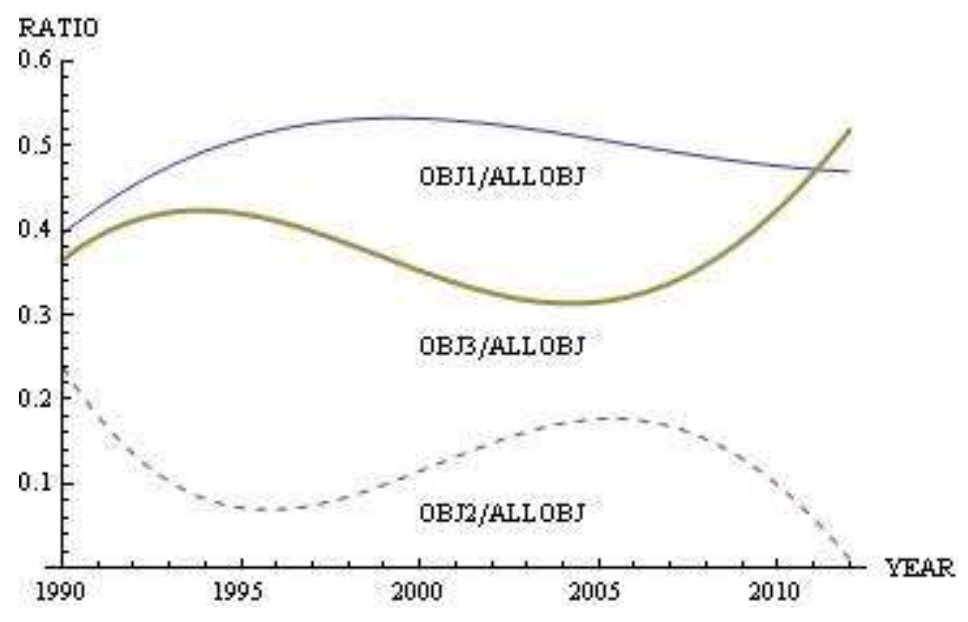

Note that these dynamics confirm that a sustainable development objective and a GHG reduction objective have been tackled with no temporal lag and with a 2-year lag, respectively.

\section{Discussion}

Although the present study provided useful results, it has some weaknesses that should be addressed in future research. First, there are no meta-preferences for coherence, efficiency, and independence that could be jointly pursued and no overall objective function to be maximized. However, the different characteristics of coherence, efficiency, and independence suggested that they should be considered separately using different analytical tools. Moreover, both the statistical results and the econometric results depend on the (sometimes subjective) allocations of EU laws among the three dichotomous classes (i.e., TRA vs. DOM, POL vs. RES, FLO vs. STO) and the 11 environmental and contextual policies (i.e., TAX, STA, PER, SUB, GRO, TEC, COS, INF, UNC, COO, RIG). However, since these criteria are well established in the literature, and the results are easily understood and interpreted, those classes and policies seem to provide plausible descriptions. Finally, the econometric analysis does not apply dummy variables to control for structural changes such as modifications of the EU Commission or EU parliament (i.e., the changes that occurred in 1989, 1994, 1999, 2004, 2009). However, the statistical analysis highlights these changes: interpolation functions for BOT1, BOT2, and BOT3 are increasing and convex from 1995 to 1999, and increasing and concave from 2000 to 2004; in contrast, the interpolation functions for TRA, POL, and STO are increasing and convex from 2005 onward).

The main strengths of the present approach are as follows: Analyses could be extended to cases or councils by the Court of Justice, which mainly aims at implementing past EU policies such as standards, and at addressing past issues such as waste management or water quality. Moreover, the results arise from complementary statistical and econometric analyses, which provides mutual support for the conclusions. Indeed, these analyses focus on different aspects of the study system: on the one hand, the relative importance values that are implicitly attached to single issues and objectives, the years when an issue increased or decreased in importance, and specific time lags in tackling single issues and objectives; on the other hand, the possible correlation between issues and the possible combination of objectives. However, the statistical and econometric analyses support each other: the statistical analysis assumes that the sum of the issue coefficients equals 1 for each objective, and the econometric analysis tests this assumption; the statistical analysis assumes the significance of some issues for some objectives, and the econometric analysis tests this for significance; the statistical analysis assumes the existence of three alternative objectives, and the econometric analysis tests this assumption; the econometric analysis highlights a temporal lag in tackling Objective 3, but the statistical analysis specifies it over 2 years; and the econometric analysis suggests a changed focus on alternative objectives, and the statistical analysis identifies the 
years when an issue increased or decreased in importance. Finally, the dataset could be updated and analyses could be applied to Objective 4 (a dematerialized economy), as stated in the Lisbon Treaty (2007).

\section{Conclusions}

The statistical and econometric analyses developed in this study based on the proposed classification criteria provided insights into how EU institutions have exploited the available policy tools to deal with environmental issues.

In particular, principles and concepts introduced in treaties and DIR were implemented via DEC and REG. Command-and-control policies (STA and GRO) were adopted first, followed by context policies (COO, then INF, then RIG), and finally by incentive policies (PER, TAX, and TEC). In other words, the overall EU environmental policy system shows coherence (i.e., consistency of the policies within the competitive general equilibrium framework). Moreover, a set of overlapping policies (here, considered as theoretically equivalent within that framework) is properly used in a timely manner to pursue all three stated objectives (here, defined as a trio of environmental issues), with Objective 2 (sustainable development) being assigned a smaller relative importance than Objective 3 (GHG reduction) and with Objective 3 having a smaller (but increasing) importance than Objective 1 (a safe environment). In other words, the overall EU environmental policy system shows efficiency (i.e., the ability of the policies to meet their objectives). Finally, objectives are stated then pursued, although sometimes with temporal lags. In other words, overall EU environmental policy system shows independence (i.e., logical priority of objectives over policies). Note that I did not consider other determinants of the EU environmental policy such as interest groups (Bunea, 2013) or external factors (Schultze \& Tosun, 2013) due to lack of reliable and comprehensive data.

I also examined whether the overall EU environmental policy system showed innovation (i.e., scientific debate about single policies). In particular, I collected data from references published between 2010 and 2013 from scopus.com related to assessment of EU policy (i.e., impacts on the environment) or on the relationships among EU policies (e.g., synergies or inconsistencies between policies), based on cross-country and cross-sector data. However, I excluded studies of the impacts on competitiveness, trade, health, and sectoral or regional case studies. My focus was on English articles in economics, environmental sciences, social sciences, and Earth sciences. I then linked the 174 policies and the 235 references to support my examination. The literature was subdivided as follows: PER (1 policy/41 references), TEC (1/11), UNC (3/6), INF (36/68), GRO (12/13), RIG (12/12), TAX (2/2), STA (79/68), and COO (28/14). Thus, DIR2003/87 (Greenhouse gas emission allowance trading scheme) and DIR2009/28 (Promotion of the use of energy from renewable sources) turned out to be the most innovative EU policies These results of my analysis were similar to those of Rogge et al. (2011). Note that some EU policies are not recent, and that the literature I analyzed refers only to the period from 2010 to 2013.

\section{References}

Aakre, S., Rübbelke, D.T.G. (2010) Adaptation to climate change in the European Union: efficiency versus equity considerations, Environmental Policy and Governance, 20 (3): 159-179.

Atkinson, R., Klausen, J.E. (2011) Understanding sustainability policy: governance, knowledge and the search for integration, Journal of Environmental Policy and Planning, 13 (3): 231-251.

Balana, B.B., Vinten, A., Slee, B. (2011) A review on cost-effectiveness analysis of agrienvironmental measures related to the EU WFD: key issues, methods, and applications, Ecological Economics, 70 (6): 1021-1031.

Biesbroek, G.R., Swart, R.J., Carter, T.R., Cowan, C., Henrichs, T., Mela, H., Morecroft, M.D., Rey, D. (2010 ) Europe adapts to climate change: comparing National Adaptation Strategies, Global Environmental Change, 20 (3): 440-450. 
Bourblanc, M., Crabbé, A., Liefferink, D., Wiering, M. (2013) The marathon of the hare and the tortoise: implementing the EU Water Framework Directive, Journal of Environmental Planning and Management, 56 (10): 1449-1467.

Brouwer, S., Rayner, T., Huitema, D. (2013) Mainstreaming climate policy: the case of climate adaptation and the implementation of EU water policy, Environment and Planning C: Government and Policy, 31 (1): 134-153.

Bunea, A. (2013) Issues, preferences and ties: determinants of interest groups' preference attainment in the EU environmental policy, Journal of European Public Policy, 20 (4): 552-570.

Cappellari, L., Jenkins, S.P. (2003) Multivariate probit regression using simulated maximum likelihood, The Stata Journal 3 (3): 278-294

Capros, P., Mantzos, L., Parousos, L., Tasios, N., Klaassen, G., Van Ierland, T. (2011) Analysis of the EU policy package on climate change and renewables, Energy Policy 39 (3): 1476-1485.

Cardenete, M.A., Guerra, A., Sancho, F. (2012) Applied General Equilibrium: An Introduction, Springer Texts in Business and Economics, Springer-Verlag, Berlin and Heidelberg

Clarida, R., Galì, J., Gertler, M. (1998) Monetary policy rules in practice: some international evidence, European Economic Review 42: 1033-1067

Clarida, R., Galí, J., Gertler, M. (2000). Monetary policy rules and macroeconomic stability: evidence and some theory, Quarterly Journal of Economics 115 (1): 147-180.

Clò, S., Battles, S., Zoppoli, P. (2013) Policy options to improve the effectiveness of the EU emissions trading system: a multi-criteria analysis, Energy Policy, 57: 477-490.

Dupont, C., Oberthür, S. (2012) Insufficient climate policy integration in EU energy policy: the importance of the long-term perspective, Journal of Contemporary European Research, 8 (2): 228-247.

EC (2013) The EU explained: Environment, http://europa.eu/pol/index_en.htm

Halpern, C. (2010) Governing despite its instruments? Instrumentation in EU environmental policy, West European Politics, 33 (1): 39-57.

Haug, C., Rayner, T., Jordan, A., Hildingsson, R., Stripple, J., Monni, S., Huitema, D., Massey, E., van Asselt, H., Berkhout, F. (2010) Navigating the dilemmas of climate policy in Europe: evidence from policy evaluation studies, Climatic Change 101 (3): 427-445.

Hiedanpää, J., Bromley, D.W. (2011) The harmonization game: reasons and rules in European biodiversity policy, Environmental Policy and Governance, 21 (2): 99-111.

Huang, H.-C., Lin, S.-C. (2006) Time-varying discrete monetary policy reaction functions, Applied Economics 38(4): 449-464.

Huang, H.-C., Shen, C.-H. (2002) Estimation of Taiwan's binary monetary policy reaction function, Journal of Economic Studies 29(3): 222-239.

Ivanov, I., Dobreva, J. (2011) Measuring sustainable governance in the European Union, International Journal of Sustainable Development and World Ecology, 18 (5): 412-423.

Jackson, A.L.R. (2011) Renewable energy vs. biodiversity: policy conflicts and the future of nature conservation, Global Environmental Change, 21 (4): 1195-1208.

Jordan, A., van Asselt, H., Berkhout, F., Huitema, D., Rayner, T. (2012) Understanding the paradoxes of multilevel governing: climate change policy in the European Union, Global Environmental Politics, 12 (2): 43-66.

Kampragou, E., Apostolaki, S., Manoli, E., Froebrich, J., Assimacopoulos, D. (2011) Towards the harmonization of water-related policies for managing drought risks across the EU, Environmental Science and Policy, 14 (7): 815-824.

Kishor, N.K., Newiak, M. (2013) The instability in the monetary policy reaction function and the estimation of monetary policy shocks, Contemporary Economic Policy, 32 (2): 390-402.

McLauchlan, A., João, E. (2012) The inherent tensions arising from attempting to carry out strategic environmental assessments on all policies, plans and programmes, Environmental Impact Assessment Review, 36: 23-33.

Melecky, M. (2012) Macroeconomic dynamics in Macedonia and Slovakia: structural estimation and comparison, Economic Modeling, 29 (4): 1377-1387. 
Newig, J., Koontz, T.M. (2013) Multi-level governance, policy implementation and participation: the EU's mandated participatory planning approach to implementing environmental policy, Journal of European Public Policy, 21 (2): 248-267.

Nilsson, M., Zamparutti, T., Petersen, J.E., Nykvist, B., Rudberg, P., McGuinn, J. (2012) Understanding policy coherence: analytical framework and examples of sector-environment policy interactions in the EU, Environmental Policy and Governance, 22 (6): 395-423.

Rietig, K. (2013) Sustainable climate policy integration in the European Union, Environmental Policy and Governance, 23 (5): 297-310.

Rogge, K.S., Schneider, M., Hoffmann, V.H. (2011) The innovation impact of the EU Emission Trading System-findings of company case studies in the German power sector, Ecological Economics 70 (3): 513-523.

Schulze, K., Tosun, J. (2013) External dimensions of European environmental policy: an analysis of environmental treaty ratification by third states, European Journal of Political Research, 52 (5): 581-607.

Sheate, W.R. (2012) Purposes, paradigms and pressure groups: accountability and sustainability in EU environmental assessment, 1985-2010, Environmental Impact Assessment Review, 33 (1): 91-102.

Shibamoto, M. (2008) The estimation of monetary policy reaction function in a data-rich environment: the case of Japan, Japan and the World Economy, 20(4): 497-520.

Spangenberg, J.H. (2010) A European methodology for sustainable development strategy reviews, Environmental Policy and Governance, 20 (2): 123-134.

Spencer, T., Fazekas, D. (2013) Distributional choices in EU climate policy: 20 years of policy practice, Climate Policy, 13 (2): 240-258.

Steurer, R., Berger, G. (2011) The EU's double-track pursuit of sustainable development in the 2000s: how Lisbon and sustainable development strategies ran past each other, International Journal of Sustainable Development and World Ecology, 18 (2): 99-108.

Steurer, R., Berger, G., Hametner, M. (2010) The vertical integration of Lisbon and sustainable development strategies across the EU: how different governance architectures shape the European coherence of policy documents, Natural Resources Forum, 34 (1): 71-84.

Swinbank, A., Daugbjerg, C. (2013) Improving EU biofuels policy? Greenhouse gas emissions, policy efficiency, and WTO compatibility, Journal of World Trade, 47 (4): 813-834.

Tol, R.S.J. (2012) A cost-benefit analysis of the EU 20/20/2020 package, Energy Policy, 49: 288295.

Wang, S., Handa, J. (2007) Monetary policy rules under a fixed exchange rate regime: empirical evidence from China, Applied Financial Economics 17(12): 941-950.

Wolkinger, B., Steininger, K.W., Damm, A., Schleicher, S., Tuerk, A., Grossman, W., Tatzber, F., Steiner, D. (2012) Implementing Europe's climate targets at the regional level, Climate Policy, 12 (6): 667-689.

Zagonari, F. (2013) Implementing a trans-boundary flood risk management plan: a method for determining willingness to cooperate and case study for the Scheldt estuary, Natural Hazards, 66 (2): 1101-1133.

\section{Supplementary Material}

Table S1. Summary of DECISIONS (DEC, directly applicable to member states). If EURATOM is unspecified, the decision was by the EC or the EEC. BOT, cases in which both sub-categories were plausible; COO, policies to improve cooperation; COS, marginal costs; DOM, domestic issues; FLO, flow-related terms; GRO, growth rate; INF = policies to share information; PER, permits; POL, pollution production; RES, resource use; RIG, policies to enforce rights; STA, standards; STO, stock-related terms; SUB, subsidies; TAX, taxes; TEC, prices of substitutive technology; TRA, trans-boundary issues; UNC, policies to reduce uncertainty.

\begin{tabular}{|c|c|c|c|c|c|c|c|}
\hline DOM/TRA & RES/POL & STO/FLO & DESCRIPTION & YEAR & NUMBER & I POL & II POL \\
\hline BOT1 & RES & STO & $\bullet$ Barcelona Convention for the protection of the Mediterranean & 1977 & 585 & COO & GRO \\
\hline
\end{tabular}




\begin{tabular}{|c|c|c|c|c|c|c|c|}
\hline BOT1 & RES & STO & -Barcelona Convention for the protection of the Mediterranean & 1981 & 420 & $\mathrm{COO}$ & GRO \\
\hline TRA & POL & FLO & -Geneva Convention on Long-Range Trans-boundary Air Pollution & 1981 & 462 & $\mathrm{COO}$ & STA \\
\hline BOT1 & RES & STO & - Conservation of Antarctic marine living resources & 1981 & 691 & GRO & $\mathrm{COO}$ \\
\hline TRA & RES & STO & •Berne Convention & 1982 & 72 & $\mathrm{COO}$ & GRO \\
\hline TRA & RES & STO & -Conservation of migratory species-Bonn Convention & 1982 & 461 & $\mathrm{COO}$ & GRO \\
\hline BOT1 & RES & STO & -Barcelona Convention for the protection of the Mediterranean & 1983 & 101 & $\mathrm{COO}$ & GRO \\
\hline BOT1 & RES & STO & -Barcelona Convention for the protection of the Mediterranean & 1984 & 132 & $\mathrm{COO}$ & GRO \\
\hline DOM & POL & STO & -Basel Convention & 1993 & 98 & $\mathrm{COO}$ & STA \\
\hline TRA & RES & STO & -The Rio de Janeiro Convention on biological diversity & 1993 & 626 & $\mathrm{COO}$ & GRO \\
\hline BOT1 & RES & STO & -Helsinki Convention on the protection of the Baltic Sea & 1994 & 156 & $\mathrm{COO}$ & GRO \\
\hline BOT1 & RES & STO & -Helsinki Convention on the protection of the Baltic Sea & 1994 & 157 & $\mathrm{COO}$ & GRO \\
\hline TRA & RES & ВОT3 & $\begin{array}{l}\text {-Helsinki Convention: trans-boundary watercourses and international } \\
\text { lakes }\end{array}$ & 1995 & 308 & $\mathrm{COO}$ & STA \\
\hline BOT1 & RES & STO & -Convention on the Protection of the Alps & 1996 & 191 & $\mathrm{COO}$ & GRO \\
\hline DOM & POL & STO & •Basel Convention & 1997 & 640 & $\mathrm{COO}$ & STA \\
\hline TRA & RES & STO & $\begin{array}{l}\text {-UN Convention to combat desertification in countries seriously } \\
\text { affected by drought }\end{array}$ & 1998 & 216 & $\mathrm{COO}$ & GRO \\
\hline BOT1 & RES & FLO & -OSPAR Convention & 1998 & 294 & $\mathrm{COO}$ & GRO \\
\hline TRA & POL & FLO & -Trans-boundary effects of industrial accidents & 1998 & 685 & STA & \\
\hline BOT1 & RES & FLO & -Convention for the Protection of the Rhine & 2000 & 706 & $\mathrm{COO}$ & STA \\
\hline DOM & POL & STO & -Protocol on Heavy Metals & 2001 & 379 & $\mathrm{COO}$ & STA \\
\hline DOM & POL & BOT3 & -Community eco-management and audit scheme (EMAS) & 2001 & 681 & INF & \\
\hline DOM & RES & STO & -Financial framework for the urban environment Archives & 2001 & 1411 & RIG & INF \\
\hline TRA & POL & STO & -Kyoto Protocol on climate change & 2002 & 358 & $\mathrm{COO}$ & STA \\
\hline DOM & POL & FLO & -Maritime safety: Bunkers Convention & 2002 & 762 & $\mathrm{COO}$ & STA \\
\hline BOT1 & BOT2 & BOT3 & -Sixth Environment Action Programme & 2002 & 1600 & $\mathrm{COO}$ & INF \\
\hline TRA & POL & STO & -Mechanism for monitoring greenhouse gas emissions & 2004 & 280 & INF & \\
\hline BOT1 & RES & STO & -Barcelona Convention for the protection of the Mediterranean & 2004 & 575 & $\mathrm{COO}$ & GRO \\
\hline DOM & BOT2 & BOT3 & -Access to information-public participation and access to justice & 2005 & 370 & RIG & INF \\
\hline DOM & BOT2 & ВОT3 & -Community eco-management and audit scheme (EMAS) & 2006 & 193 & INF & \\
\hline DOM & POL & FLO & -Stockholm Convention on persistent organic pollutants (POPs) & 2006 & 507 & $\mathrm{COO}$ & STA \\
\hline TRA & POL & FLO & $\begin{array}{l}\text { The Rotterdam Convention on the international trade in hazardous } \\
\text { chemicals }\end{array}$ & 2006 & 730 & $\mathrm{COO}$ & STA \\
\hline DOM & BOT2 & BOT3 & •Seventh Framework Programme (2007 to 2013) & 2006 & 969 & INF & $\mathrm{COO}$ \\
\hline DOM & POL & ВОТ3 & $\begin{array}{l}\text {-Competitiveness and Innovation Framework Programme (CIP; } 2007 \text { to } \\
\text { 2013) }\end{array}$ & 2006 & 1639 & INF & $\mathrm{COO}$ \\
\hline DOM & BOT2 & ВОT3 & •Seventh Framework Programme (2007 to 2013) & 2006 & 1982 & INF & $\mathrm{COO}$ \\
\hline DOM & POL & FLO & -Financing of civil protection measures (2007 to 2013) EURATOM & 2007 & 162 & RIG & $\mathrm{COO}$ \\
\hline DOM & POL & FLO & -Civil Protection Mechanism EURATOM & 2007 & 779 & RIG & \\
\hline DOM & POL & ВОТ3 & $\begin{array}{l}\text {-Scientific Committees for consumer safety-public health and the } \\
\text { environment }\end{array}$ & 2008 & 721 & INF & $\mathrm{COO}$ \\
\hline TRA & POL & STO & -Reducing greenhouse gases by 2020 & 2009 & 406 & STA & \\
\hline BOT1 & RES & STO & -Barcelona Convention for the protection of the Mediterranean & 2010 & 631 & $\mathrm{COO}$ & GRO \\
\hline
\end{tabular}

Table S2. Summary of DIRECTIVES (DIR, to be implemented by EU's member states). If EURATOM is unspecified, the decision was by the EC or the EEC. BOT, cases in which both sub-categories were plausible; COO, policies to improve cooperation; COS, marginal costs; DOM, domestic issues; FLO, flow-related terms;

GRO, growth rate; INF = policies to share information; PER, permits; POL, pollution production; RES, resource use; RIG, policies to enforce rights; STA, standards; STO, stock-related terms; SUB, subsidies; TAX, taxes; TEC, prices of substitutive technology; TRA, trans-boundary issues; UNC, policies to reduce uncertainty.

\begin{tabular}{|c|c|c|l|l|c|c|c|}
\hline DOM/TRA & RES/POL & STO/FLO & DESCRIPTION & YEAR & NUMBER & I POL & II POL \\
\hline DOM & POL & FLO & $\bullet$ Motor vehicles with trailers: permissible sound level & 1970 & 157 & STA & \\
\hline DOM & POL & FLO & $\bullet$ Bathing water quality (until 2014) & 1976 & 160 & STA & \\
\hline DOM & POL & FLO & $\bullet$ Regulatory framework for the management of chemicals (REACH) & 1976 & 769 & INF & STA \\
\hline DOM & POL & STO & $\bullet$ Disposal of titanium dioxide industrial waste & 1978 & 176 & STA & \\
\hline DOM & POL & STO & $\bullet$ Other substances: protection of groundwater & STA & 680 & 68 \\
\hline
\end{tabular}




\begin{tabular}{|c|c|c|c|c|c|c|c|}
\hline DOM & POL & FLO & -Environmental quality standards applicable to surface water & 1982 & 176 & STA & \\
\hline DOM & POL & STO & -Surveillance and monitoring of titanium dioxide waste & 1982 & 883 & INF & STA \\
\hline TRA & RES & STO & -Protection of certain seal species & 1983 & 129 & GRO & \\
\hline DOM & POL & FLO & -Environmental quality standards applicable to surface water & 1983 & 513 & STA & \\
\hline DOM & POL & FLO & -Environmental quality standards applicable to surface water & 1984 & 156 & STA & \\
\hline DOM & POL & FLO & -Environmental quality standards applicable to surface water & 1984 & 491 & STA & \\
\hline DOM & ВОТ2 & ВОТ3 & $\begin{array}{l}- \text { Assessment of the effects of plans and programmes (Impact } \\
\text { Assessment) }\end{array}$ & 1985 & 337 & INF & \\
\hline DOM & POL & STO & -Use of sewage sludge in agriculture & 1986 & 278 & STA & \\
\hline DOM & POL & FLO & -Environmental quality standards applicable to surface water & 1986 & 280 & STA & \\
\hline TRA & RES & STO & -Deliberate release of genetically modified organisms (GMOs) & 1990 & 220 & STA & INF \\
\hline BOT1 & BOT2 & BOT3 & - Freedom of access to information & 1990 & 313 & INF & RIG \\
\hline DOM & POL & FLO & -Regulatory framework for the management of chemicals (REACH) & 1991 & 155 & INF & STA \\
\hline DOM & POL & FLO & -Urban wastewater treatment & 1991 & 271 & STA & \\
\hline DOM & POL & FLO & -Agricultural nitrates (nitrates) & 1991 & 676 & STA & \\
\hline DOM & POL & STO & $\begin{array}{l}\text { - Controlled management of hazardous wastes (until the end of 2010) } \\
\text { Archives }\end{array}$ & 1991 & 689 & STA & INF \\
\hline DOM & POL & STO & $\begin{array}{l}\text {-Reduction of pollution caused by waste from the titanium dioxide } \\
\text { industry }\end{array}$ & 1992 & 112 & STA & \\
\hline TRA & RES & STO & •Natural habitats (Natura 2000) & 1993 & 43 & GRO & \\
\hline DOM & POL & FLO & $\cdot$ Regulatory framework for the management of chemicals (REACH) & 1993 & 67 & INF & STA \\
\hline DOM & POL & FLO & -Regulatory framework for the management of chemicals (REACH) & 1993 & 105 & INF & STA \\
\hline DOM & POL & STO & -Packaging and packaging waste & 1994 & 62 & STA & \\
\hline DOM & POL & FLO & $\cdot$ Recovery of petrol vapors during storage & 1994 & 63 & STA & \\
\hline DOM & POL & FLO & $\begin{array}{l}\text {-Disposal of polychlorinated biphenyls (PCBs) and polychlorinated } \\
\text { terphenyls (PCTs) }\end{array}$ & 1996 & 59 & STA & \\
\hline DOM & POL & FLO & -European Pollutant Release and Transfer Register (PRTR) & 1996 & 61 & INF & \\
\hline DOM & POL & FLO & -Major accidents involving dangerous substances & 1996 & 82 & STA & \\
\hline DOM & POL & FLO & •Non-road mobile machinery: gaseous pollutants & 1997 & 68 & STA & \\
\hline DOM & POL & FLO & -Quality of petrol and diesel fuels: sulfur and lead & 1998 & 70 & STA & \\
\hline DOM & POL & FLO & $\cdot$ Quality of drinking water & 1998 & 83 & STA & \\
\hline DOM & POL & FLO & -Reducing the emissions of volatile organic compounds (VOCs) & 1999 & 13 & STA & \\
\hline BOT1 & RES & FLO & -The keeping of wild animals in zoos & 1999 & 22 & RIG & \\
\hline DOM & POL & STO & $\cdot$ Landfill of wastes & 1999 & 31 & STA & \\
\hline DOM & POL & FLO & $\cdot$ Regulatory framework for the management of chemicals (REACH) & 1999 & 45 & INF & STA \\
\hline DOM & POL & FLO & -Taxation of heavy goods vehicles: Eurovignette Directive & 1999 & 62 & TAX & \\
\hline DOM & POL & FLO & -Information on the fuel consumption and $\mathrm{CO}_{2}$ emissions of new cars & 1999 & 94 & INF & \\
\hline TRA & RES & STO & -International Dolphin Conservation Programme & 1999 & 337 & GRO & INF \\
\hline DOM & POL & FLO & -Noise emission by equipment used outdoors & 2000 & 14 & STA & \\
\hline DOM & POL & FLO & $\cdot$ Regulatory framework for the management of chemicals (REACH) & 2000 & 21 & INF & STA \\
\hline DOM & POL & FLO & -Pollutant gases of wheeled agricultural or forestry tractors & 2000 & 25 & STA & \\
\hline DOM & POL & STO & •End-of-life vehicles & 2000 & 53 & STA & \\
\hline DOM & POL & STO & -Port facilities for ship-generated wastes and cargo residues & 2000 & 59 & STA & \\
\hline BOT1 & RES & BOT3 & -Water protection and management (Water Framework Directive) & 2000 & 60 & INF & $\mathrm{COO}$ \\
\hline DOM & POL & STO & -Waste incineration & 2000 & 76 & STA & \\
\hline TRA & RES & STO & -Deliberate release of genetically modified organisms (GMOs) & 2001 & 18 & STA & \\
\hline TRA & RES & STO & -Traceability and labeling of GMOs & 2001 & 18 & STA & \\
\hline DOM & BOT2 & BOT3 & \begin{tabular}{|l} 
Assessment of the effects of plans and programmes (Strategic \\
Assessment)
\end{tabular} & 2001 & 42 & RIG & INF \\
\hline DOM & POL & FLO & -Pollutants from large combustion plants & 2001 & 80 & STA & \\
\hline DOM & POL & FLO & -National emission ceilings for certain atmospheric pollutants & 2001 & 81 & STA & \\
\hline DOM & POL & FLO & -Noise management at EU airports & 2002 & 30 & STA & \\
\hline DOM & POL & FLO & -Assessment and management of environmental noise & 2002 & 49 & STA & \\
\hline BOT1 & POL & FLO & -Maritime safety: prevention of pollution from ships & 2002 & 84 & STA & \\
\hline DOM & POL & STO & -Waste electrical and electronic equipment & 2002 & 95 & STA & \\
\hline DOM & POL & STO & -Waste electrical and electronic equipment & 2002 & 96 & STA & \\
\hline BOT1 & BOT2 & ВОT3 & - Freedom of access to information & 2003 & 4 & INF & \\
\hline
\end{tabular}




\begin{tabular}{|c|c|c|c|c|c|c|c|}
\hline DOM & RES & FLO & •Motor vehicles: use of biofuels Archives & 2003 & 30 & STA & TEC \\
\hline TRA & POL & STO & -Greenhouse gas emission allowance trading scheme & 2003 & 87 & PER & \\
\hline DOM & BOT2 & FLO & $\begin{array}{l}\text { - Community framework for the taxation of energy products and } \\
\text { electricity }\end{array}$ & 2003 & 96 & TAX & INF \\
\hline DOM & BOT2 & FLO & •Environmental liability & 2004 & 35 & RIG & STA \\
\hline DOM & POL & FLO & -Ship-source pollution and criminal penalties & 2005 & 35 & STA & RIG \\
\hline DOM & POL & STO & -The reusing, recycling, and recovery of motor vehicles & 2005 & 64 & STA & \\
\hline DOM & POL & FLO & -Bathing water quality & 2006 & 7 & STA & \\
\hline DOM & POL & FLO & $\begin{array}{l}\text {-Protection of the aquatic environment against discharges of dangerous } \\
\text { substances (until 2013) }\end{array}$ & 2006 & 11 & STA & \\
\hline TRA & POL & STO & -Carbon dioxide capture and geological storage & 2006 & 12 & STA & \\
\hline DOM & POL & STO & -Management of wastes from extractive industries & 2006 & 21 & STA & \\
\hline TRA & POL & FLO & •Emissions from air conditioning systems in motor vehicles & 2006 & 40 & STA & \\
\hline DOM & POL & FLO & -Water suitable for fish reproduction & 2006 & 44 & STA & \\
\hline DOM & POL & STO & -Disposal of spent batteries and accumulators & 2006 & 66 & STA & \\
\hline DOM & POL & FLO & -Quality of shellfish waters & 2006 & 113 & STA & \\
\hline DOM & POL & STO & -Shipments of radioactive waste: supervision and control EURATOM & 2006 & 117 & STA & \\
\hline DOM & POL & STO & -Protection of groundwater against pollution & 2006 & 118 & STA & \\
\hline BOT1 & POL & FLO & -Infrastructure for Spatial Information (INSPIRE) & 2007 & 2 & INF & \\
\hline BOT1 & RES & FLO & -Flood management and evaluation & 2007 & 60 & UNC & $\mathrm{COO}$ \\
\hline DOM & POL & FLO & -Motor vehicles with trailers: permissible sound level & 2007 & 734 & STA & \\
\hline DOM & POL & ВОT3 & -Integrated pollution prevention and control (until 2013; IPPC) & 2008 & 1 & INF & STA \\
\hline DOM & POL & FLO & -Pure air for Europe & 2008 & 50 & STA & \\
\hline BOT1 & RES & STO & -Strategy for the marine environment (Marine Strategy Framework) & 2008 & 56 & INF & $\mathrm{COO}$ \\
\hline DOM & POL & STO & -Directive on wastes & 2008 & 98 & STA & \\
\hline DOM & BOT2 & FLO & -Protection of the environment through criminal law & 2008 & 99 & RIG & \\
\hline DOM & POL & FLO & -Environmental quality standards applicable to surface water & 2008 & 105 & STA & \\
\hline DOM & RES & FLO & -Promotion of the use of energy from renewable sources & 2009 & 28 & TEC & \\
\hline TRA & POL & STO & - Carbon dioxide capture and geological storage & 2009 & 31 & STA & \\
\hline DOM & POL & FLO & -Clean and energy-efficient road transport vehicles & 2009 & 33 & STA & \\
\hline TRA & RES & STO & -Contained use of genetically modified micro-organisms (GMMs) & 2009 & 41 & STA & \\
\hline DOM & POL & FLO & -Petrol vapor recovery during refueling of vehicles & 2009 & 126 & STA & \\
\hline TRA & RES & STO & -Conservation of wild birds & 2009 & 147 & GRO & \\
\hline DOM & RES & FLO & -Protection of laboratory animals & 2010 & 63 & RIG & \\
\hline DOM & POL & FLO & -Industrial emissions & 2010 & 75 & STA & \\
\hline DOM & POL & STO & -Management of spent fuels and radioactive wastes EURATOM & 2011 & 70 & UNC & \\
\hline
\end{tabular}

Table S3. Summary of REGULATIONS (REG, directly applicable to member states). If EURATOM is unspecified, the decision was by the EC or the EEC. BOT, cases in which both sub-categories were plausible; COO, policies to improve cooperation; COS, marginal costs; DOM, domestic issues; FLO, flow-related terms;

GRO, growth rate; INF = policies to share information; PER, permits; POL, pollution production; RES, resource use; RIG, policies to enforce rights; STA, standards; STO, stock-related terms; SUB, subsidies; TAX, taxes; TEC, prices of substitutive technology; TRA, trans-boundary issues; UNC, policies to reduce uncertainty.

\begin{tabular}{|c|c|c|l|c|c|c|c|}
\hline DOM/TRA & RES/POL & STO/FLO & DESCRIPTION & YEAR & NUMBER & I POL & II POL \\
\hline DOM & POL & FLO & $\cdot$ Production and labeling of organic products & 1991 & 2092 & INF & STA \\
\hline DOM & POL & FLO & $\cdot$ Regulatory framework for the management of chemicals (REACH) & 1993 & 793 & INF & STA \\
\hline DOM & POL & STO & $\cdot$ Shipments of radioactive substances & 1993 & 1493 & UNC & STA \\
\hline DOM & POL & FLO & $\cdot$ Regulatory framework for the management of chemicals (REACH) & 1994 & 1488 & INF & STA \\
\hline DOM & POL & FLO & $\cdot$-Novel foods and food ingredients & 1997 & 258 & STA & \\
\hline TRA & RES & STO & $\cdot$ Endangered species of wild fauna and flora (CITES) & 1997 & 338 & GRO & \\
\hline DOM & BOT2 & FLO & $\cdot$ Environmental inspections: minimum criteria & 2001 & 331 & INF & \\
\hline DOM & BOT2 & BOT3 & $\cdot$ Community eco-management and audit scheme (EMAS) & 2001 & 761 & INF & \\
\hline TRA & RES & STO & $\cdot$ Conservation of certain stocks of migratory fish & 2001 & 1936 & GRO & \\
\hline BOT1 & BOT2 & BOT3 & $\cdot$ Development and integrated management of coastal zones & 2002 & 413 & GRO & INF \\
\hline DOM & POL & STO & $\cdot$ Waste management statistics & 2002 & 2150 & INF & \\
\hline
\end{tabular}




\begin{tabular}{|c|c|c|c|c|c|c|c|}
\hline BOT1 & RES & STO & - Conservation and exploitation of marine resources & 2002 & 2371 & GRO & \\
\hline BOT1 & POL & FLO & -Maritime safety: prohibition of organotin compounds on ships & 2003 & 782 & STA & \\
\hline DOM & POL & FLO & -The Marco Polo II programme & 2003 & 1382 & STA & \\
\hline TRA & RES & STO & -Traceability and labeling of GMOs & 2003 & 1830 & STA & \\
\hline TRA & RES & STO & -Transboundary movement of genetically modified organisms & 2003 & 1946 & STA & \\
\hline BOT1 & POL & FLO & -Framework for creation of the Single European Sky (SES) & 2004 & 549 & STA & \\
\hline DOM & POL & FLO & -Detergents & 2004 & 648 & STA & \\
\hline TRA & RES & STO & -Protecting cetaceans against incidental catch & 2004 & 812 & GRO & \\
\hline DOM & POL & FLO & •European Pollutant Release and Transfer Register (PRTR) & 2006 & 166 & INF & \\
\hline TRA & POL & STO & -Reduction in fluorinated greenhouse gases & 2006 & 842 & STA & \\
\hline DOM & POL & STO & -Shipments of waste & 2006 & 1013 & STA & \\
\hline DOM & BOT2 & BOT3 & -Application of the Aarhus Convention to EU institutions & 2006 & 1367 & $\mathrm{COO}$ & RIG \\
\hline DOM & POL & FLO & -The Marco Polo II programme & 2006 & 1692 & INF & STA \\
\hline DOM & POL & FLO & -Regulatory framework for the management of chemicals (REACH) & 2006 & 1907 & INF & STA \\
\hline DOM & RES & BOT3 & -Programme LIFE+ & 2007 & 614 & RIG & $\mathrm{COO}$ \\
\hline TRA & RES & STO & -Alien and locally absent species & 2007 & 708 & GRO & \\
\hline TRA & POL & FLO & -Reduction of pollutant emissions from light vehicles & 2007 & 715 & STA & \\
\hline DOM & POL & FLO & -Production and labeling of organic products & 2007 & 834 & INF & \\
\hline TRA & RES & FLO & -Ban on trade in cat and dog fur & 2007 & 1523 & RIG & \\
\hline DOM & POL & FLO & •Clean Sky & 2008 & 71 & STA & \\
\hline TRA & POL & FLO & $\begin{array}{l}\text {-The Rotterdam Convention on the international trade in hazardous } \\
\text { chemicals }\end{array}$ & 2008 & 689 & $\mathrm{COO}$ & STA \\
\hline DOM & RES & STO & $\begin{array}{l}\text { Protection of vulnerable marine ecosystems in the high seas from } \\
\text { bottom fishing }\end{array}$ & 2008 & 734 & GRO & \\
\hline TRA & POL & STO & •Export and storage of mercury & 2008 & 1102 & STA & \\
\hline TRA & RES & STO & •Food and Feed (GMO) & 2008 & 1829 & STA & \\
\hline TRA & POL & FLO & - Reduction in $\mathrm{CO}_{2}$ emissions of new passenger cars & 2009 & 443 & STA & \\
\hline TRA & POL & FLO & -Emissions from heavy duty vehicles (Euro VI): certification rules & 2009 & 595 & INF & \\
\hline TRA & POL & STO & -Substances affecting the ozone layer & 2009 & 1005 & STA & \\
\hline TRA & POL & FLO & -Trade in seal products & 2009 & 1007 & STA & \\
\hline DOM & BOT2 & BOT3 & -Community eco-management and audit scheme (EMAS) & 2009 & 1221 & INF & \\
\hline DOM & POL & ВОT3 & •Ecolabeling & 2010 & 66 & INF & \\
\hline DOM & BOT2 & BOT3 & •European Earth monitoring programme (GMES) & 2010 & 911 & $\mathrm{COO}$ & INF \\
\hline DOM & RES & STO & •Fight against illegal logging & 2010 & 995 & RIG & \\
\hline TRA & POL & FLO & -Reduction of carbon dioxide emissions from light commercial vehicles & 2011 & 510 & STA & \\
\hline
\end{tabular}




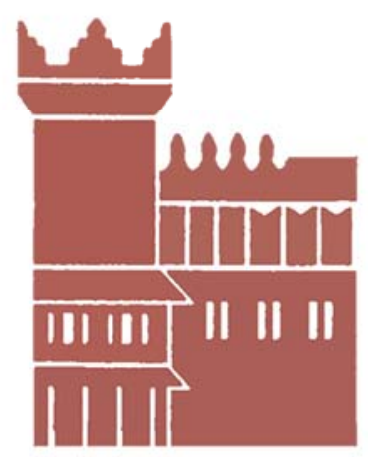

Alma Mater Studiorum - Università di Bologna DEPARTMENT OF ECONOMICS

Strada Maggiore 45

40125 Bologna - Italy

Tel. +39051 2092604

Fax +390512092664

http://www.dse.unibo.it 